\title{
Evolution of DS-1-like human G2P[4] rotaviruses assessed by complete genome analyses
}

Correspondence

Giovanni M. Giammanco

giovanni.giammanco@unipa.it

Received 3 July 2013

Accepted 23 September 2013
Giovanni M. Giammanco, ${ }^{1}$ Floriana Bonura, ${ }^{1}$ Mark Zeller, ${ }^{2}$ Elisabeth Heylen, ${ }^{2}$ Marc Van Ranst, ${ }^{2}$ Vito Martella, ${ }^{3}$ Kristián Bányai, ${ }^{4}$ Jelle Matthijnssens ${ }^{2}$ and Simona De Grazia ${ }^{1}$

\author{
${ }^{1}$ Dipartimento di Scienze per la Promozione della Salute 'G. D'Alessandro', Università di Palermo, \\ Italy \\ ${ }^{2}$ Laboratory of Clinical and Epidemiological Virology, Department of Microbiology and Immunology, \\ Rega Institute for Medical Research, University of Leuven, Leuven, Belgium \\ ${ }^{3}$ Dipartimento di Sanità Pubblica e Zootecnia, Università Aldo Moro di Bari, Valenzano, Italy \\ ${ }^{4}$ Institute for Veterinary Medical Research, Centre for Agricultural Research, \\ Hungarian Academy of Sciences, Budapest, Hungary
}

Group A rotaviruses (RVAs) are a leading cause of viral gastroenteritis in children, with G2P[4] RVA being one of the most common human strains worldwide. The complete genome sequences of nine G2P[4] RVA strains, selected from a 26-year archival collection (1985-2011) established in Palermo, Italy, were determined. A strain associated with a peak of G2P[4] RVA activity in 1996 resembled a reassortant strain identified in Kenya in 1982 and differed completely in genomic make up from more recent strains that circulated during 2004-2011. Conversely, the 20042011 G2P[4] RVAs were genetically more similar to contemporary RVA strains circulating globally. Recent G2P[4] strains possessed either single or multiple genome segments (VP1, VP3 and/or NSP4) likely derived from ruminant viruses through intra-genotype reassortment. Amino acid substitutions were selected and maintained over time in the VP7 and VP8* antigenic proteins, allowing the circulation of two contemporary G2P[4] variants to be distinguished. Altogether, these findings suggest that major changes in the genomic composition of recent G2P[4] RVAs occurred in the early 2000 s, leading to the appearance of a novel variant of the DS-1-like genotype constellation. Whether the modifications observed in the neutralizing antigens and in the genome composition of modern G2P[4] RVAs may affect the long-term effectiveness of the vaccination programmes remains to be explored.

\section{INTRODUCTION}

Group A rotaviruses (RVAs), family Reoviridae, are major pathogens causing gastroenteritis in young children, with a mortality rate of 453000 deaths annually (Tate et al., 2012). RVA has a double-stranded RNA genome made of 11 segments which encode six structural proteins (VP1-VP4, VP6 and VP7) and six non-structural proteins (NSP1NSP6) (Estes \& Kapikian, 2007). Based on the constellation

The GenBank/EMBL/DDBJ accession numbers for the nine G2P[4] RVA complete genome sequences determined in this work are KC178763-KC178771 (for VP1), KC178772-KC178780 (VP2), KC178781-KC178789 (VP3), KC178790-KC178798 (VP4) KC178799-KC178807 (VP6), KC178808-KC178816 (VP7), KC178718-KC178726 (NSP1), KC178727-KC178735 (NSP2), KC178736-KC178744 (NSP3), KC178745-KC178753 (NSP4) and KC178754-KC178762 (NSP5).

A supplementary figure is available with the online version of this paper. of segments composing the genome, three human genotypes have been established: Wa-like (genotype constellation 1), DS-1-like (genotype constellation 2) and AU-1-like (genotype constellation 3) (Matthijnssens et al., 2008a; Nakagomi \& Nakagomi, 1989). RVA strains are classified into G- and P-types based on genetic and antigenic diversity of the two outer capsid proteins, VP7 (G-genotypes) and VP4 (P-genotypes), respectively (Estes \& Kapikian, 2007). To date, 27 different G- and 37 Pgenotypes have been described in humans and animals (Matthijnssens et al., 2011; Trojnar et al., 2013). The majority of RVAs infecting humans are: G1P[8], G2P[4], G3P[8], G4P[8], G9P[8] and G12P[8] (Bányai et al., 2012; Santos \& Hoshino, 2005). The segmented nature of the RVA genome enables assortment of different individual gene segments of parental virus strains during mixed infections, generating reassortant virus strains. In 2008, the Rotavirus Classification Working Group (RCWG) 
proposed a full genome-based classification scheme allowing the differentiation of genotypes for the 11 RVA RNA segments, providing an ideal platform for deciphering the complex genetic diversity of RVAs (Matthijnssens et al., 2008a,b).

Although the global prevalence rate of G2P[4] strains is lower than that of G1P[8] strains, G2P[4] RVAs are recognized as a common cause of viral diarrhoea in humans, frequently reaching an epidemiological predominance in some geographical areas (Antunes et al., 2009; Chouikha et al., 2011; Dey et al., 2009; Doan et al., 2011; Iturriza-Gómara et al., 2011; Kirkwood et al., 2009; Paul et al., 2008; Santos \& Hoshino, 2005; Todd et al., 2010). Notably, increased circulation of G2P[4] strains has been signalled after the introduction of RVA vaccination in several countries (Gurgel et al., 2007; Nakagomi et al., 2008; Zeller et al., 2010), although epidemiological investigations in South America have revealed that an increase in the circulation of G2P[4] RVA strains also occurred in the same time frames in countries in which no universal RVA vaccination programmes were established (Gurgel et al., 2007; Matthijnssens et al., 2009, 2012). Although it is very likely that vaccination will have some effect on the genotype distribution of circulating RVA strains, it is unclear what the long-term effects of this vaccine-derived selective pressure will be compared with other factors shaping natural genotype fluctuations (Matthijnssens et al., 2012).

VP7 sequence analysis of G2 RVAs detected over a 35year period revealed that G2 VP7 lineages follow temporal patterns of evolution. The oldest G2 strains, sharing the same lineage (G2-I) as the prototype strain DS-1, were not detected after 1990, while a lineage of G2 RVAs (G2-II) circulated for almost 15 years between 1991 and 2005. In the 1990s a novel variant of a distinct lineage emerged (IVa-1) and spread all over the world, followed by another lineage IV variant (IVa-3) in the 2000s. Virtually all the G2 RVAs detected in the last decade
(2001-2009) belong to those two variants (Doan et al., 2011).

RVA surveillance in Palermo, Italy, has been conducted uninterruptedly since 1985, revealing yearly prevalence rates of RVAs ranging from $20 \%$ to $50 \%$ among children aged $<5$ years hospitalized with gastroenteritis (Arista et al., 1986, 1990, 1997, 2003, 2004, 2005; De Grazia et al., 2007). In the 26-year period 1985-2011, the prevalence of G2P[4] RVAs in the paediatric population of Palermo showed yearly fluctuations (Arista et al., 2005; De Grazia et al., 2007), with peaks in 1985, 1996 to 1998, 2003 and 2004, 2006 to 2008, 2010 and 2011 (Fig. 1). Interestingly, the G2 strains identified between 2002 and 2004 did not react with the G2 type-specific monoclonal antibody (mAb) RV5:3, which was related to a change ( $\mathrm{D}$ to $\mathrm{N}$ ) in antigenic region A at residue 96 (Arista et al., 2005) and is a hallmark of all recent G2 RVAs (lineage IVa) (Doan et al., 2011). In order to explore in more detail the observed antigenic/genetic diversity in G2P[4] RVAs and to understand whether these changes were limited to the outer capsid proteins or also affected the overall genetic structure, the complete genomes of nine selected G2P[4] RVA strains isolated in Palermo, Italy, between 1996 and 2011 were determined.

\section{METHODS}

Sample collection. Uninterrupted surveillance on RVA circulation has been conducted in Palermo, southern Italy, for 26 years (19852011). Stool samples were collected from children under 5 years admitted at the 'G. Di Cristina' Children's Hospital of Palermo for acute gastroenteritis. Since the rotavirus season in Palermo is generally delayed with respect to the usual winter peak and includes the end of winter and spring (the peak circulation is in March and April), this paper is written using years instead of seasons.

Nucleic acid extraction and G- and P-genotyping by seminested PCR. Viral RNA was extracted from $10 \%$ faecal suspension using a QIAamp Viral RNA mini kit (Qiagen), according to the manufacturer's instructions.

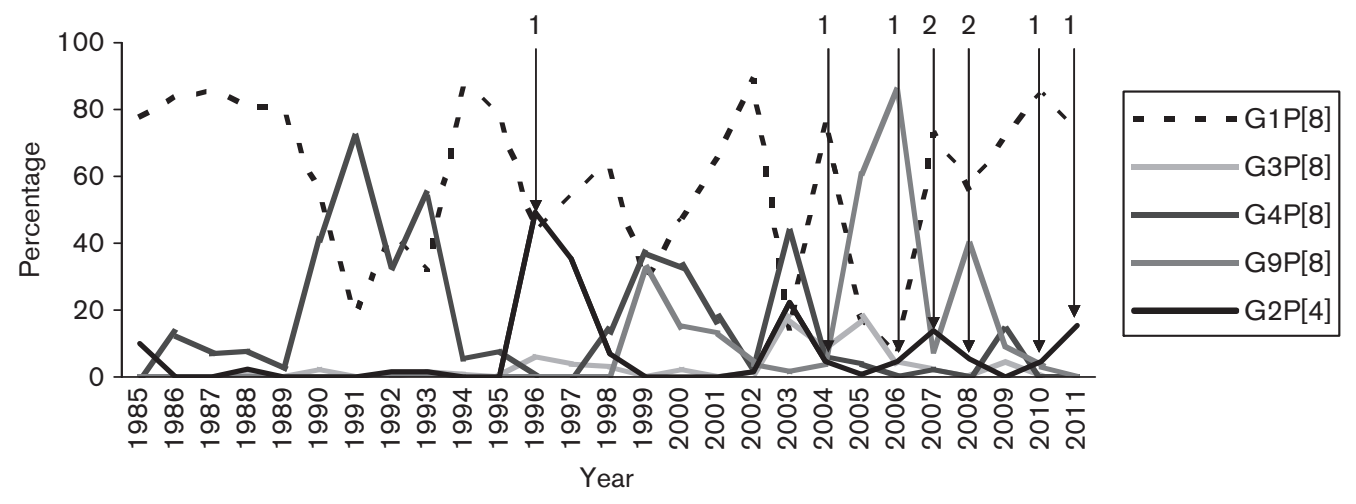

Fig. 1. Circulation of RVA genotypes in Palermo, Italy, from 1985 to 2011 . Arrows indicate the year of collection and number of $\mathrm{G} 2 \mathrm{P}[4]$ isolates selected for whole genome analysis. 


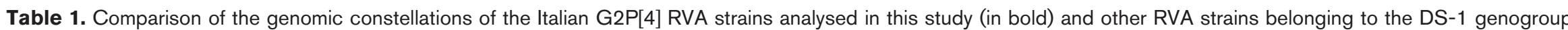

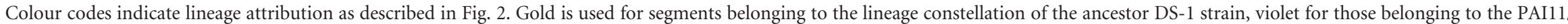

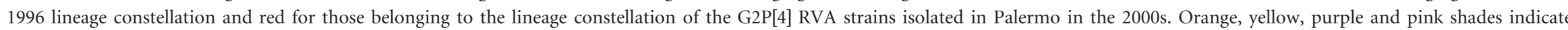

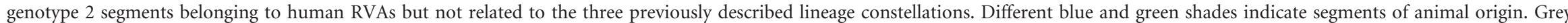
indicates the genotype 2 segments typical of the vaccine strain SC2-9.

\begin{tabular}{|c|c|c|c|c|c|c|c|c|c|c|c|c|c|}
\hline & & VP7 & VP4 & VP6 & VP1 & VP2 & VP3 & NSP1 & NSP2 & NSP3 & NSP4 & NSP5 & \\
\hline RVA/Human-tc/USA/DS-1/1976/G2P1B[4] & Human & G2 & $\mathrm{P}[4]$ & $\mathrm{I} 2$ & $\mathrm{R} 2$ & $\mathrm{C} 2$ & M2 & A2 & $\mathrm{N} 2$ & $\mathrm{~T} 2$ & E2 & $\mathrm{H} 2$ & Human \\
\hline RVA/Human-tc/KEN/AK26/1982/G2P[4] & Human & G2 & $\mathrm{P}[4]$ & $\mathrm{I} 2$ & $\mathrm{R} 2$ & $\mathrm{C} 2$ & M2 & A2 & N1 & $\mathrm{T} 2$ & E2 & $\mathrm{H} 2$ & \\
\hline RVA/Human-tc/KEN/D205/1989/G2P[4] & Human & G2 & $\mathrm{P}[4]$ & $\mathrm{I} 2$ & $\mathrm{R} 2$ & $\mathrm{C} 2$ & M2 & $\mathrm{A} 2$ & N2 & $\mathrm{T} 2$ & $\mathrm{E} 2$ & $\mathrm{H} 2$ & \\
\hline RVA/Human-wt/AUS/95A/1995/G2Px & Human & G2 & & & & & & & & & & & \\
\hline RVA/Human-wt/CHN/TB-Chen/1996/G2P[4] & Human & G2 & $\mathrm{P}[4]$ & $\mathrm{I} 2$ & $\mathrm{R} 2$ & $\mathrm{C} 2$ & M2 & $\mathrm{A} 2$ & $\mathrm{~N} 2$ & $\mathrm{~T} 2$ & $\mathrm{E} 2$ & $\mathrm{H}_{2}$ & \\
\hline RVA/Human-wt/ZAF/64SB/1996/G2P[4] & Human & G2 & & & & & & & & & & & \\
\hline RVA/Human-wt/ITA/PAI11/1996/G2P4 & Human & G2 & 4 & I2 & $\mathrm{R} 2$ & $\mathrm{C} 2$ & M2 & A2 & N1 & $\mathrm{T} 2$ & $\mathrm{E} 2$ & $\mathrm{H} 2$ & \\
\hline RVA/Human-wt/ZAF/906SB/1998/G2P[6] & Human & & & & & & & & & & & & \\
\hline RVA/Human-wt/ZAF/GR10924/1999/G9P[6] & Human & G9 & $\mathrm{P}[6]$ & $\mathrm{I} 2$ & $\mathrm{R} 2$ & $\mathrm{C} 2$ & M2 & $\mathrm{A} 2$ & N2 & $\mathrm{T} 2$ & $\mathrm{E} 2$ & $\mathrm{H} 2$ & \\
\hline RVA/Human-wt/BGD/RV161/2000/G12P[6] & Human & G12 & $\mathrm{P}[6]$ & $\mathrm{I} 2$ & $\mathrm{R} 2$ & $\mathrm{C} 2$ & M2 & $\mathrm{A} 2$ & N2 & $\mathrm{T} 2$ & E1 & $\mathrm{H} 2$ & \\
\hline RVA/Human-wt/MWI/1473/2001/G8P[4] & Human & G8 & $\mathrm{P}[4]$ & $\mathrm{I} 2$ & $\mathrm{R} 2$ & $\mathrm{C} 2$ & M2 & A2 & N2 & $\mathrm{T} 2$ & E2 & $\mathrm{H} 2$ & \\
\hline RVA/Human-wt/BEL/B1711/2002/G6P[6] & Human & G6 & $\mathrm{P}[6]$ & $\mathrm{I} 2$ & $\mathrm{R} 2$ & $\mathrm{C} 2$ & M2 & A2 & $\mathrm{N} 2$ & $\mathrm{~T} 2$ & $\mathrm{E} 2$ & $\mathrm{H} 2$ & \\
\hline RVA/Human-wt/BGD/N26/2002/G12P[6] & Human & G12 & $\mathrm{P}[6]$ & $\mathrm{I} 2$ & $\mathrm{R} 2$ & $\mathrm{C} 2$ & M2 & $\mathrm{A} 2$ & $\mathrm{~N} 1$ & $\mathrm{~T} 2$ & E6 & $\mathrm{H} 2$ & \\
\hline RVA/Human-wt/COD/DRC88/2003/G8P[8] & Human & G8 & $\mathrm{P}[8]$ & $\mathrm{I} 2$ & $\mathrm{R} 2$ & $\mathrm{C} 2$ & M2 & A2 & N2 & $\mathrm{T} 2$ & $\mathrm{E} 2$ & $\mathrm{H} 2$ & \\
\hline RVA/Human-wt/ITA/PA3/2004/G2P[4] & Human & G2 & $\mathrm{P}[4]$ & $\mathrm{I} 2$ & R2 & $\mathrm{C} 2$ & M2 & A2 & N2 & $\mathrm{T} 2$ & E2 & $\mathrm{H} 2$ & \\
\hline RVA/Human-wt/BGD/MMC88/2005/G2P[4] & Human & G2 & $\mathrm{P}[4]$ & $\mathrm{I} 2$ & $\mathrm{R} 2$ & $\mathrm{C} 2$ & $\mathrm{M} 2$ & A2 & N2 & $\mathrm{T} 2$ & $\mathrm{E} 2$ & $\mathrm{H} 2$ & \\
\hline RVA/Human-wt/USA/LB2772/2005/G2P[4] & Human & G2 & $\mathrm{P}[4]$ & $\mathrm{I} 2$ & $\mathrm{R} 2$ & $\mathrm{C} 2$ & M2 & $\mathrm{A} 2$ & $\mathrm{~N} 2$ & $\mathrm{~T} 2$ & $\mathrm{E} 2$ & $\mathrm{H} 2$ & \\
\hline RVA/Human-wt/BGD/MMC6/2005/G2P[4] & Human & G2 & $\mathrm{P}[4]$ & $\mathrm{I} 2$ & $\mathrm{R} 2$ & $\mathrm{C} 2$ & M2 & A2 & $\mathrm{N} 2$ & $\mathrm{~T} 2$ & E2 & $\mathrm{H} 2$ & \\
\hline RVA/Human-wt/ITA/PA150/2006/G2P[4] & Human & G2 & $\mathrm{P}[4]$ & $\mathrm{I} 2$ & $\mathrm{R} 2$ & $\mathrm{C} 2$ & M2 & $\mathrm{A} 2$ & $\mathrm{~N} 2$ & $\mathrm{~T} 2$ & E2 & $\mathrm{H} 2$ & \\
\hline RVA/Human-wt/IND/265/2007/G10P[6] & Human & & & & & & & & & & $\mathrm{E} 2$ & & \\
\hline RVA/Human-wt/ITA/PA83/2007/G2P[4] & Human & G2 & $\mathrm{P}[4]$ & $\mathrm{I} 2$ & R2 & $\mathrm{C} 2$ & M2 & A2 & $\mathrm{N} 2$ & $\mathrm{~T} 2$ & E2 & $\mathrm{H} 2$ & \\
\hline RVA/Human-wt/ITA/PA108/2007/G2P[4] & Human & G2 & $\mathrm{P}[4]$ & $\mathrm{I} 2$ & $\mathrm{R} 2$ & $\mathrm{C} 2$ & M2 & A2 & N2 & $\mathrm{T} 2$ & $\mathrm{E} 2$ & $\mathrm{H} 2$ & \\
\hline RVA/Human-wt/ITA/PA84/2008/G2P[4] & Human & G2 & $\mathrm{P}[4]$ & $\mathrm{I} 2$ & R2 & $\mathrm{C} 2$ & M2 & A2 & N2 & $\mathrm{T} 2$ & $\mathrm{E} 2$ & $\mathrm{H} 2$ & \\
\hline RVA/Human-wt/ITA/PA17/2008/G2P[4] & Human & G2 & $\mathrm{P}[4]$ & $\mathrm{I} 2$ & $\mathrm{R} 2$ & $\mathrm{C} 2$ & $\mathrm{M} 2$ & $\mathrm{~A} 2$ & $\mathrm{~N} 2$ & $\mathrm{~T} 2$ & $\mathrm{E} 2$ & $\mathrm{H} 2$ & \\
\hline RVA/Human-wt/RUS/Omsk08-475/2008/G2P[4] & Human & G2 & $\mathrm{P}[4]$ & $\mathrm{I} 2$ & & & & & & & & & \\
\hline RVA/Human-wt/IND/UP-BE-1/2009/GxPx & Human & & & & & & & & & & $\mathrm{E} 2$ & & \\
\hline RVA/Human-wt/DEU/GER1H/2009/G8P[4] & Human & G8 & $\mathrm{P}[4]$ & $\mathrm{I} 2$ & $\mathrm{R} 2$ & $\mathrm{C} 2$ & M2 & $\mathrm{A} 2$ & & $\mathrm{~T} 2$ & & $\mathrm{H} 2$ & \\
\hline RVA/Human-wt/ZAF/3203WC/2009/G2P[4] & Human & G2 & $\mathrm{P}[4]$ & $\mathrm{I} 2$ & $\mathrm{R} 2$ & $\mathrm{C} 2$ & M2 & A2 & N2 & $\mathrm{T} 2$ & E2 & $\mathrm{H} 2$ & \\
\hline RVA/Human-wt/BEL/F01322/2009/G3P[6] & Human & G3 & $\mathrm{P}[6]$ & $\mathrm{I} 2$ & $\mathrm{R} 2$ & $\mathrm{C} 2$ & M2 & A2 & N2 & $\mathrm{T} 2$ & E2 & $\mathrm{H} 2$ & \\
\hline RVA/Human-wt/ITA/PA130/2010/G2P[4] & Human & G2 & $\mathrm{P}[4]$ & I2 & R2 & $\mathrm{C} 2$ & M2 & A2 & N2 & $\mathrm{T} 2$ & E2 & $\mathrm{H} 2$ & \\
\hline RVA/Human-wt/ITA/PA133/2011/G2P[4] & Human & $\mathrm{G} 2$ & $\mathrm{P}[4]$ & I2 & $\mathrm{R} 2$ & $\mathrm{C} 2$ & M2 & $\mathrm{A} 2$ & N2 & $\mathrm{T} 2$ & $\mathrm{E} 2$ & $\mathrm{H} 2$ & \\
\hline RVA/Human-wt/HUN/Hun5/1997/G6P[14] & Human & G6 & $\mathrm{P}[14]$ & $\mathrm{I} 2$ & $\mathrm{R} 2$ & $\mathrm{C} 2$ & $\mathrm{M} 2$ & A11 & $\mathrm{N} 2$ & T6 & $\mathrm{E} 2$ & $\mathrm{H} 3$ & Animal or \\
\hline RVA/Goat-tc/BGD/GO34/1999/G6P[1] & Goat & G6 & $\mathrm{P}[1]$ & $\mathrm{I} 2$ & $\mathrm{R} 2$ & $\mathrm{C} 2$ & $\mathrm{M} 2$ & A11 & $\mathrm{N} 2$ & T6 & $\mathrm{E} 2$ & $\mathrm{H} 3$ & animal-derived \\
\hline RVA/Human-wt/HUN/BP1879/2003/G6P[14] & Human & G6 & $\mathrm{P}[14]$ & - & $\mathrm{R} 2$ & - & 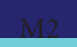 & A11 & & T6 & & $\mathrm{H} 3$ & \\
\hline RVA/Human-wt/HUN/BP1062/2004/G8P[14] & Human & G8 & $\mathrm{P}[14]$ & $\mathrm{I} 2$ & $\mathrm{R} 2$ & $\mathrm{C} 2$ & M2 & A11 & $\mathrm{N} 2$ & T6 & E2 & H3 & \\
\hline RVA/Cow-wt/IND/MP/B-47/2008/GxPx & Cow & & & & & & & & & & $\mathrm{E} 2$ & & \\
\hline RVA/Cow-wt/IND/MP-B-100/2008/GxPx & Cow & & & & & & & & & & $\mathrm{E} 2$ & & \\
\hline RVA/Vaccine/USA/RotaTeq-SC2-9/1992/G2P7[5] & Human/cow & G & P7[5] & $\mathrm{I} 2$ & $\mathrm{R} 2$ & $\mathrm{C} 2$ & M1 & $\mathrm{A} 3$ & N2 & T6 & $\mathrm{E} 2$ & $\mathrm{H} 3$ & Vaccin \\
\hline
\end{tabular}


(a)

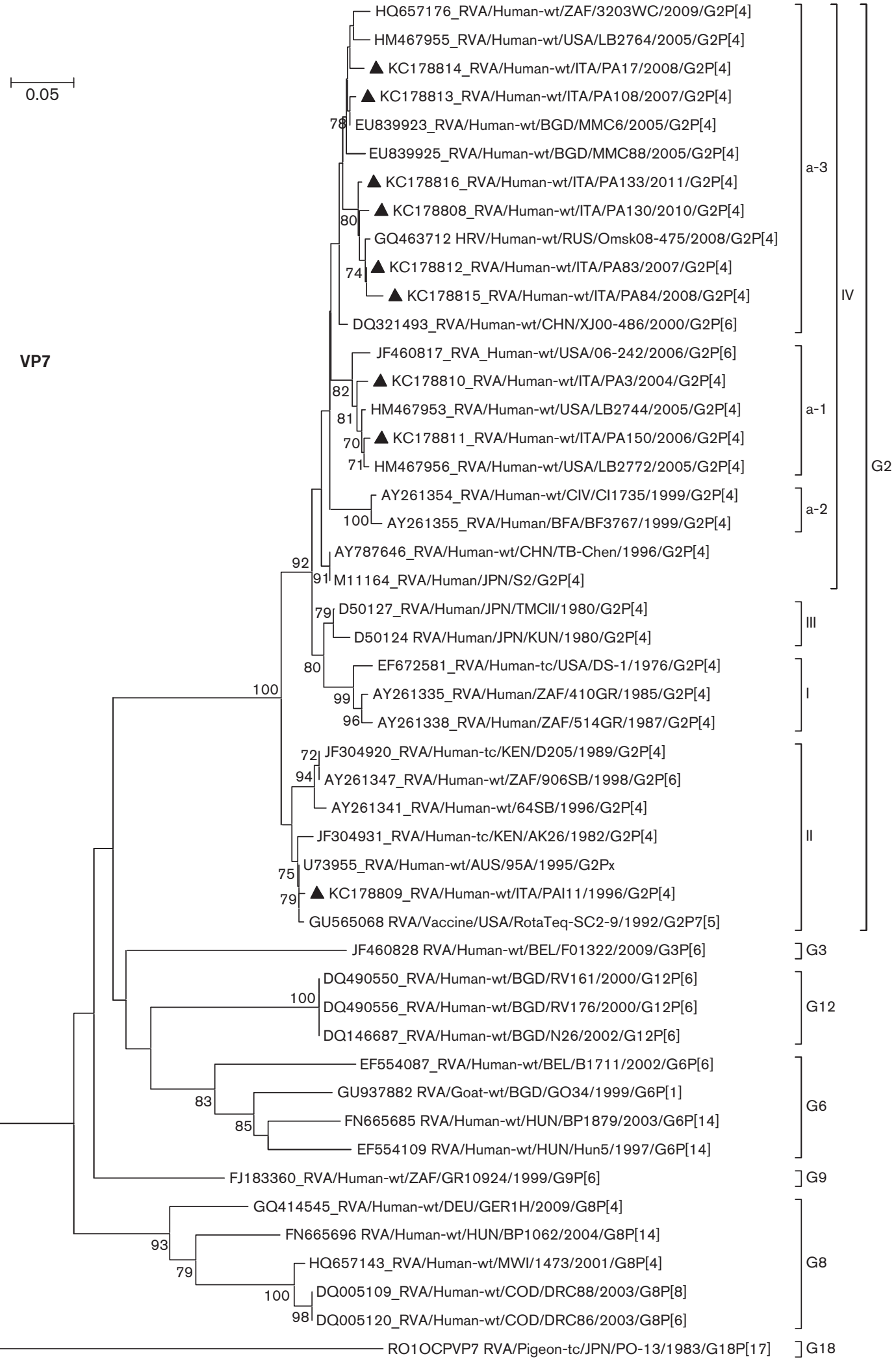

Fig. 2. Phylogenetic trees based on the full-length nucleotide sequences of RVA VP7 (a), VP4 (b), VP6 (c), VP1 to VP3 (d-f), and NSP1 to NSP5 $(\mathrm{g}-\mathrm{k})$ genes. Bootstrap values (1000 replicates) above $69 \%$ are shown at branch nodes. The number of nucleotide substitutions per site is indicated by the scale bars. The strains analysed in this study are marked with a triangle. VP7 lineages and sublineages of G2 strains and VP4 lineages of P[4] strains are indicated according to Doan et al. $(2011,2012)$. NSP2 lineages within the N1 genotype are indicated according to Donker et al. (2011). 
(b)

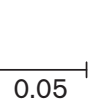

VP4
[ $\mathbf{\Delta}$ KC178795_RVA/Human-wt/ITA/PA83/2007/G2P[4]

A KC178791_RVA/Human-wt/ITA/PA133/2011/G2P[4]

83. GQ463711 HRV/Human-wt/RUS/Omsk08-475/2008/G2P[4]

A KC178790_RVA/Human-wt/ITA/PA130/2010/G2P[4]

- HM467943_RVA/Human-wt/USA/LB2764/2005/G2P[4]

79

EU839950_RVA/Human-wt/BGD/MMC6/2005/G2P[4]

A KC178796_RVA/Human-wt/ITA/PA108/2007/G2P[4]

8\$ HO641373_RVA/Human-wt/BGD/MMC88/2005/G2P[4]

A KC178797_RVA/Human-wt/ITA/PA17/2008/G2P[4]

AC178793_RVA/Human-wt/ITA/PA3/2004/G2P[4]

A KC178798_RVA/Human-wt/ITA/PA84/2008/G2P[4]

[GQ414543_RVA/Human-wt/DEU/GER1H/2009/G8P[4]

$77^{98}$

74

KC178794_RVA/Human-wt/ITA/PA150/2006/G2P[4]

4

HM467941_RVA/Human-wt/USA/LB2744/2005/G2P[4]

87

[ AY787644_RVA/Human-wt/CHN/TB-Chen/1996/G2P[4]

8L DQ172838_RVA/Human-wt/ITA/PAH41/1993/G2P[4]

_ AB733131 RVA/Human-tc/JPN/KUN/1980/G2P[4]

100 _ HQ650119_RVA/Human-tc/USA/DS-1/1976/G2P[4]

98 $\Delta$ KC178792_RVA/Human-wt/ITA/PAl11/1996/G2P[4]

[JF304929_RVA/Human-tc/KEN/AK26/1982/G2P[4]

82 _ JF304918_RVA/Human-tc/KEN/D205/1989/G2P[4]

97 _ HO657141_RVA/Human-wt/MWI/1473/2001/G8P[4]

_ DQ005111_RVA/Human-wt/COD/DRC88/2003/G8P[8]

98

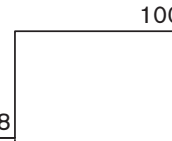

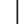

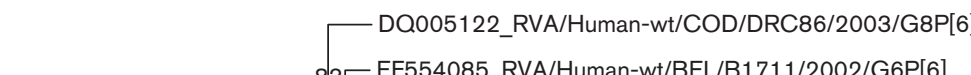

100

_EF554085_RVA/Human-wt/BEL/B1711/2002/G6P[6]

[JF460826 RVA/Human-wt/BEL/F01322/2009/G3P[6]

[FJ183356_RVA/Human-wt/ZAF/GR10924/1999/G9P[6]

95

DQ490548_RVA/Human-wt/BGD/RV161/2000/G12P[6]

[DQ490554_RVA/Human-wt/BGD/RV176/2000/G12P[6]

GU565066 RVA/Vaccine/USA/RotaTeq-SC2-9/1992/G2P7[5]

GU937880 RVA/Goat-wt/BGD/GO34/1999/G6P[1]

FN665691 RVA/Human-wt/HUN/BP1062/2004/G8P[14]

$100 \mathrm{~L}$ FN665680 RVA/Human-wt/HUN/BP1879/2003/G6P[14]

AB009632 RVA/Pigeon-tc/JPN/PO-13/1983/G18P[17]

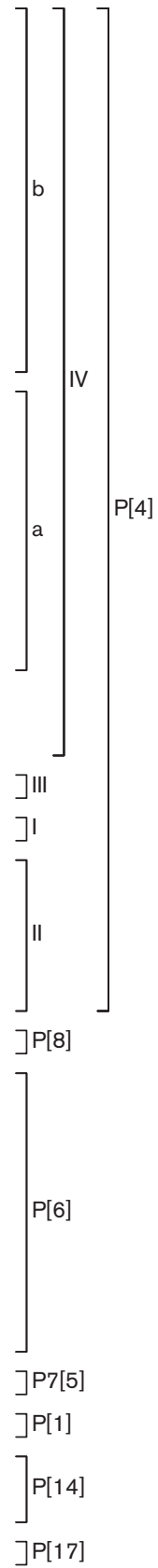

Fig. 2. (continued)

The extracted RNA was reverse transcribed as previously described (Iturriza-Gomara et al., 1999). Rotavirus G- and P-genotyping was performed using semi-nested multiplex PCRs (Gentsch et al., 1992; Gouvea et al., 1990; Iturriza-Gómara et al., 2004; Martella et al., 2004). All strains typable by reverse transcription-polymerase chain reaction (RT-PCR) were further investigated by direct sequencing of VP7 and VP4 for phylogenetic analysis.

Whole genome sequencing and phylogenetic analysis. A selection of G2P[4] strains representative of the surveillance period, for which a sufficient amount of the original faecal sample was available, was subjected to whole genome analysis (Fig. 1). The complete genome sequencing, including the $5^{\prime}$ and $3^{\prime}$ termini of each genome segment, of the selected RVA strains was performed as described elsewhere (Matthijnssens et al., 2006). The genotypes of the G2P[4] RVA strains were determined according to the genotyping recommendations of the RCWG using the RotaC online classification tool (http://rotac.regatools. be) (Maes et al., 2009). Cognate genome sequences were individually compared with whole genome RVA sequences available in GenBank. When reassortment was suspected, the most similar sequences available in GenBank were also added to the corresponding tree even if sequences of other gene segments were not available. Phylogenetic analysis was performed using the software MEGA5 (Tamura et al., 2011). Phylogenetic trees were constructed using the neighbour-joining method and 
(c)

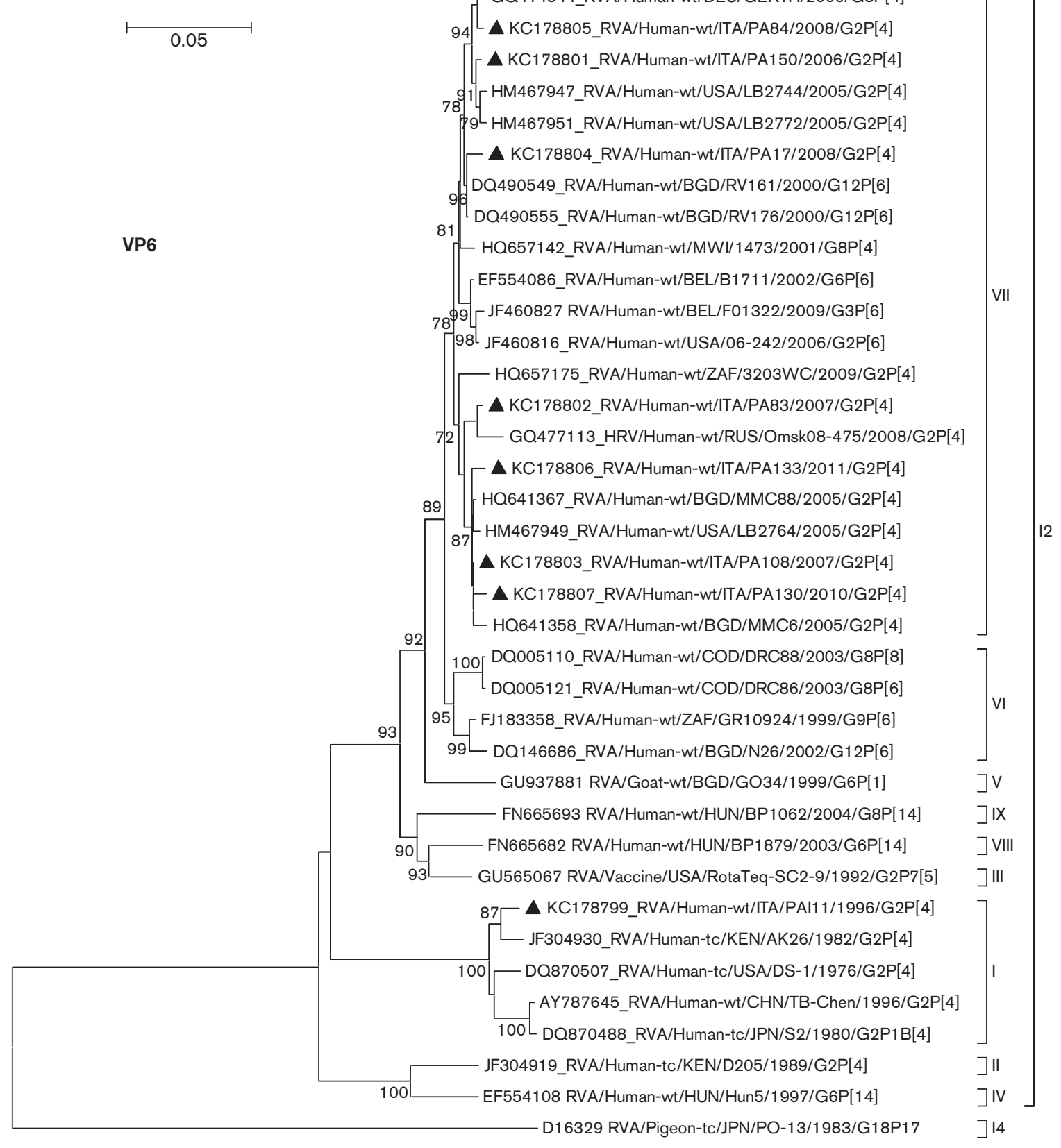

Fig. 2. (continued)

Kimura's two-parameter model with 1000 bootstrap replicates. Lineage designation for the various genome segments followed the outlines of the existing literature and was substantiated by sequence comparison and phylogenetic analysis of our sequence datasets.

Accession numbers. GenBank accession numbers for each individual genomic segment are: KC178763-KC178771 (VP1); KC178772KC178780 (VP2); KC178781-KC178789 (VP3); KC178790-KC178798 (VP4); KC178799-KC178807 (VP6); KC178808-KC178816 (VP7); KC178718-KC178726 (NSP1); KC178727-KC178735 (NSP2); KC178736KC178744 (NSP3); KC178745-KC178753 (NSP4); $\quad \mathrm{KC178754-}$ KC178762 (NSP5).

\section{RESULTS}

Representative G2P[4] strains were selected on the basis of preliminary phylogenetic analysis of 38 partial VP7 sequences ( $>456 \mathrm{nt}$ in length) detected between 1993 and 2011. We were not able to produce sequences from strains from before 1993 (Fig. S1, available in JGV Online). Nine G2 RVA strains, detected in seven different years of increased G2P[4] circulation, 1996 (PAI11/1996), 2004 (PA3/2004), 2006 (PA150/2006), 2007 (PA83/2007 and PA108/2007), 2008 (PA17/2008 and PA84/2008), 2010 
(d)

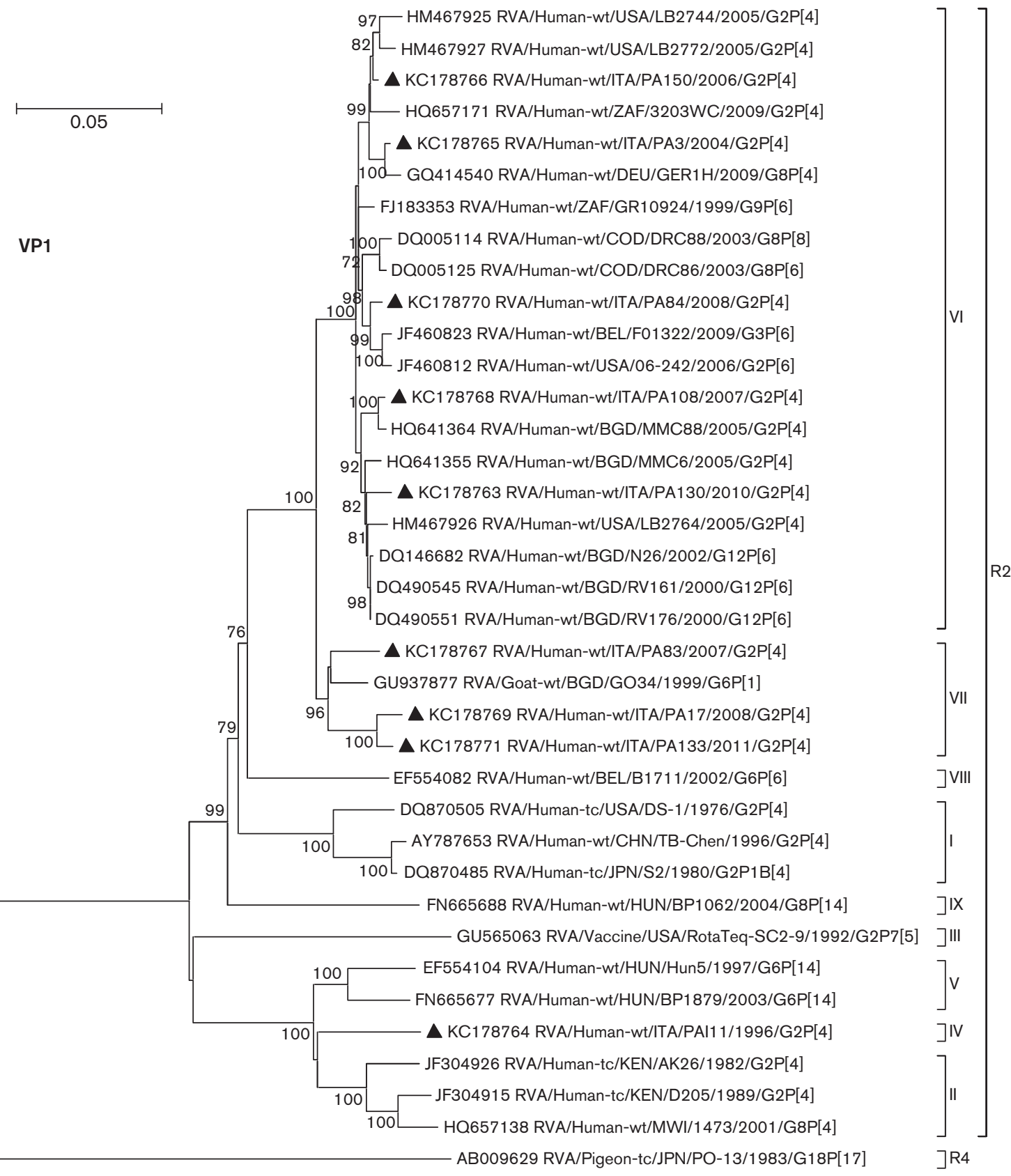

Fig. 2. (continued)

(PA130/2010) and 2011 (PA133/2011), were chosen for complete genome analysis. Although the same VP7 gene can be found in different genetic backgrounds, the nine strains were selected as representative of the various VP7 lineages, and of clusters within different lineages, as detected over the 1993-2011 surveillance period (Fig. S1). Once complete genome sequences were obtained, the genotype for each of the 11 gene segments was defined using the online RVA classification tool RotaC at http:// rotac.regatools.be (Maes et al., 2009). This analysis allowed unambiguous genotype assignment of all Italian G2P[4] strains as G2-P[4]-I2-R2-C2-M2-A2-N2-T2-E2$\mathrm{H} 2$, except for strain PAI11/1996, which possessed an N1 NSP2 genotype. Complete genotype assignments of the Italian strains, together with those of other representative G2P[4] RVA strains, including reference strain DS-1, are shown in Table 1.

Phylogenetic trees of all 11 genome segments were constructed (Fig. 2). Overall, the VP1-VP4, VP6-VP7 
(e)

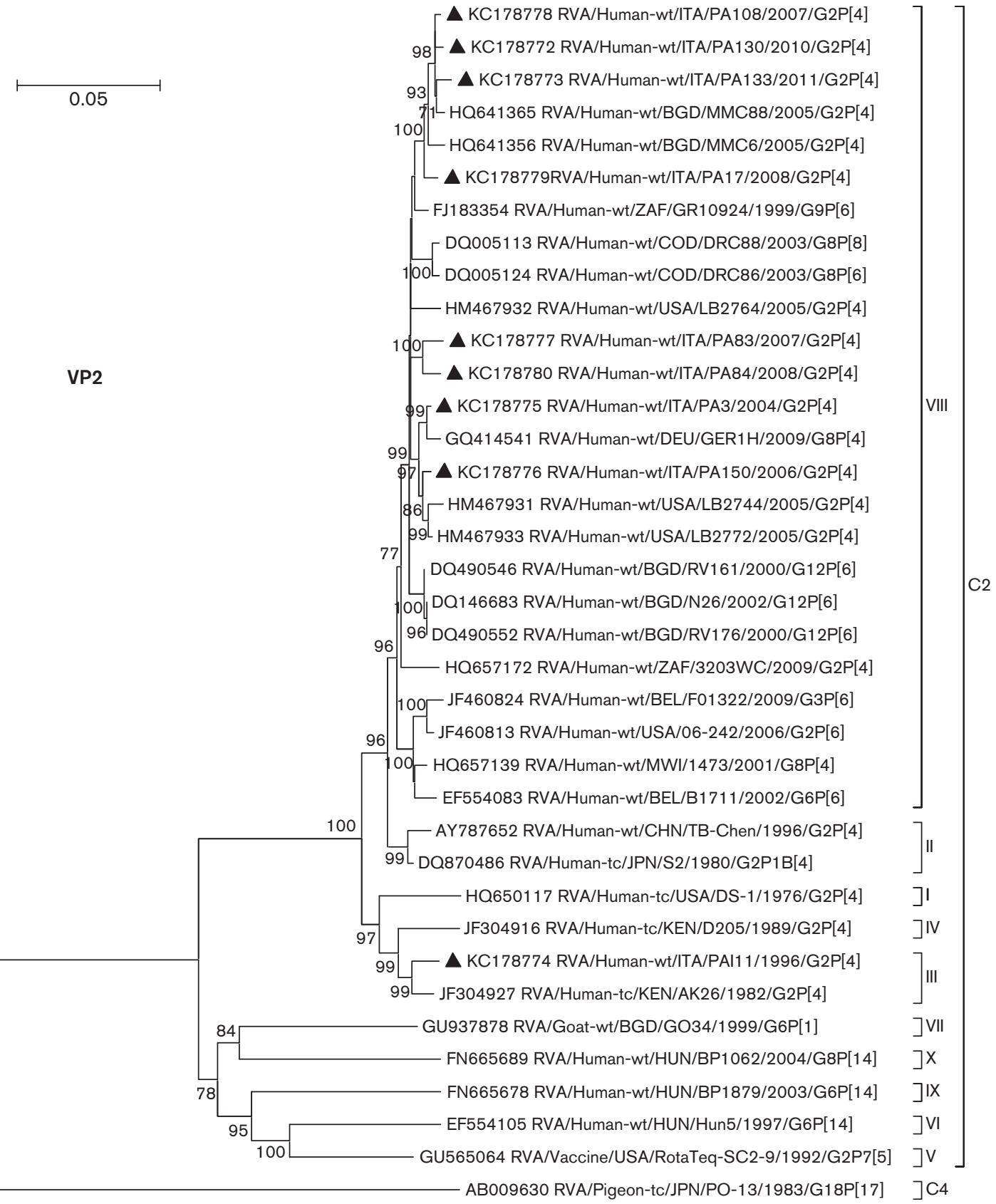

Fig. 2. (continued)

and NSP1-NSP5 gene segments of the Italian G2P[4] strains showed a variable degree of sequence identity, ranging from $>81.6 \%$ (at nt level) for NSP2 to $>95 \%$ for NSP3. As a general rule, for each genome, segment lineages were defined ad hoc based on observed clustering patterns in the phylogeny and indicated with roman numerals, but for VP7, VP4 and NSP2 N1 genotypes the same lineage designations were used as defined by Doan et al. (2011, 2012) and Donker et al. (2011), respectively (Fig. 2). Lineage attribution is shown in Table 1 using colour coding to distinguish segments belonging to different lineages from each other and indicating the main lineage constellations. According to the proposed lineage segregation, none of the Italian strains matched the genetic pattern of the prototype DS-1 strain isolated in the 1970s. Also, in the VP7 tree all the analysed viruses, except for strain PAI11/ 1996, were only distantly related to the G2-reassortant vaccine strain SC2-9. Strain PAI11/1996 showed a close phylogenetic clustering with AK26 Kenyan strain in all genome segments with the exception of VP1, NSP2 and NSP4 (Fig. 2). Several genome segments of PAI11/1996 were also related to another Kenyan strain, D205 (VP2, 


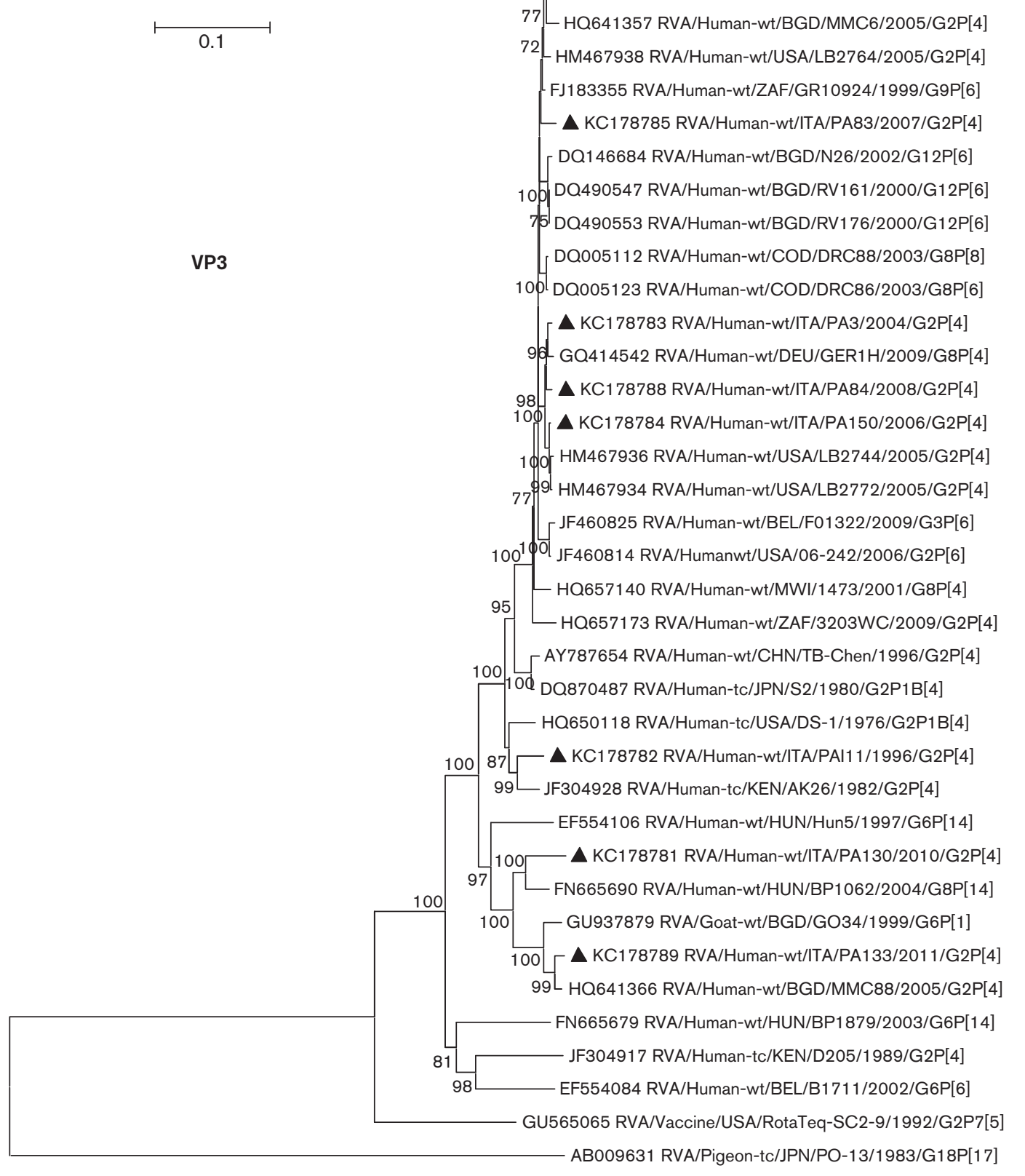

55 KC178786 RVA/Human-wt/TA/PA108/2007/G2P[4]

96 - KC178787 RVA/Human-wt/ITA/PA17/2008/G2P[4]

77 HQ641357 RVA/Human-wt/BGD/MMC6/2005/G2P[4] FJ183355 RVA/Human-wt/ZAF/GR10924/1999/G9P[6]

- $\Delta$ KC178785 RVA/Human-wt/ITA/PA83/2007/G2P[4] DQ146684 RVA/Human-wt/BGD/N26/2002/G12P[6]

DQ490547 RVA/Human-wt/BGD/RV161/2000/G12P[6]

DQ490553 RVA/Human-wt/BGD/RV176/2000/G12P[6]

DQ005112 RVA/Human-wt/COD/DRC88/2003/G8P[8]

VI

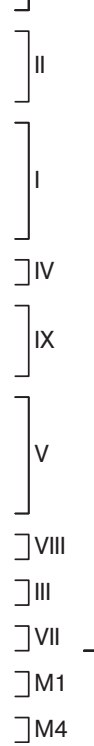

Fig. 2. (continued)

VP4, VP7 and NSP5), to the Malawian strain MWI/1473 (VP4) and, in VP7, to G2 strains from South Africa (64SB and 906SB) and Australia (95A) (Table 1). For the other eight Italian G2P[4] strains, detected between 2004 and 2011, all genome segments clustered separately from those of strain PAI11/1996. Strains PA3/2004 and PA150/2006 formed a novel lineage constellation, which was shared also by RVA strains detected in different continents - MMC6 from Bangladesh, 3203WC from South Africa and LB2772 from the USA - suggesting a worldwide circulation of this lineage constellation within the DS-1-like RVA strains. The most recent Italian strains, PA83/2007, PA108/2007, PA17/ 2008, PA84/2008, PA130/2010 and PA133/2011, also retained a lineage constellation very similar to the former, although exhibiting one or more segments of different origin. Strains PA83/2007, PA17/2008 and PA133/2011 share their VP1 and VP3 reassortant segments with the caprine strain GO34 and the reassortant human strain MMC88, both from Bangladesh (Fig. 2d, f, Table 1). Strain PA130/2010 displayed a VP3 similar to the Hungarian animal-like human RVA strain BP1062 (Fig. 2f, Table 1) (Bányai et al., 2010). The 2004-2011 G2P[4] strains 
(g)

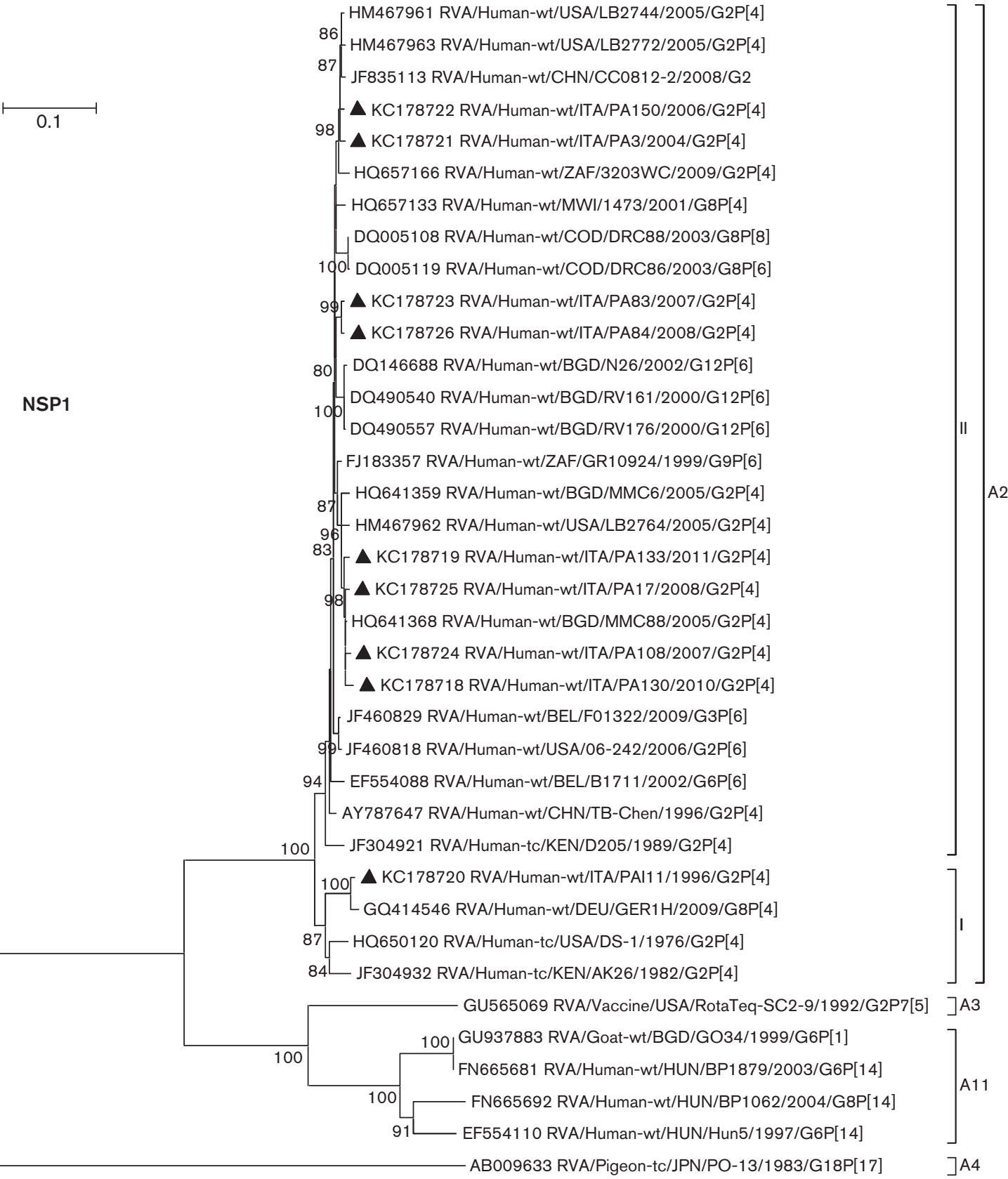

Fig. 2. (continued)

segregated into three different lineages within the NSP4 E2 genotype (Fig. 2j, Table 1), with strains PA3/2004, PA150/ 2006 and PA83/2007 clustering together with contemporary G2P[4] RVA strains detected all over the world and with TB-Chen strain isolated in China in 1996, strain PA84/2008 and PA133/2011 clustering with human RVAs from central and eastern Europe, and strains PA108/2007, PA17/2008 and PA130/2010 segregating with human and ruminant RVAs from India.

In the VP7 tree, strain PAI11/1996 clustered in the G2II lineage, while the 2004-2011 RVAs clustered into two
G2-IV sublineages, diverging by at least 3.1\% (nt) from each other, and including Italian viruses detected in 20042006 (sublineage IVa-1) and in 2007-2011 (sublineage IVa3), respectively (Fig. 2a), suggesting temporally related patterns of segregation. When the VP7 amino acid alignment (Fig. 3) was inspected in detail, strain PAI11/ 1996 was seen to differ only in three residues from the G2 vaccine strain SC2-9 (lineage II) and in 16 residues from the prototype G2 strain DS-1 (lineage I), with most changes ( $3 / 3$ and $10 / 16$, respectively) accumulating within the variable regions (VRs). The 2004-2011 G2 Italian RVAs 
(h)

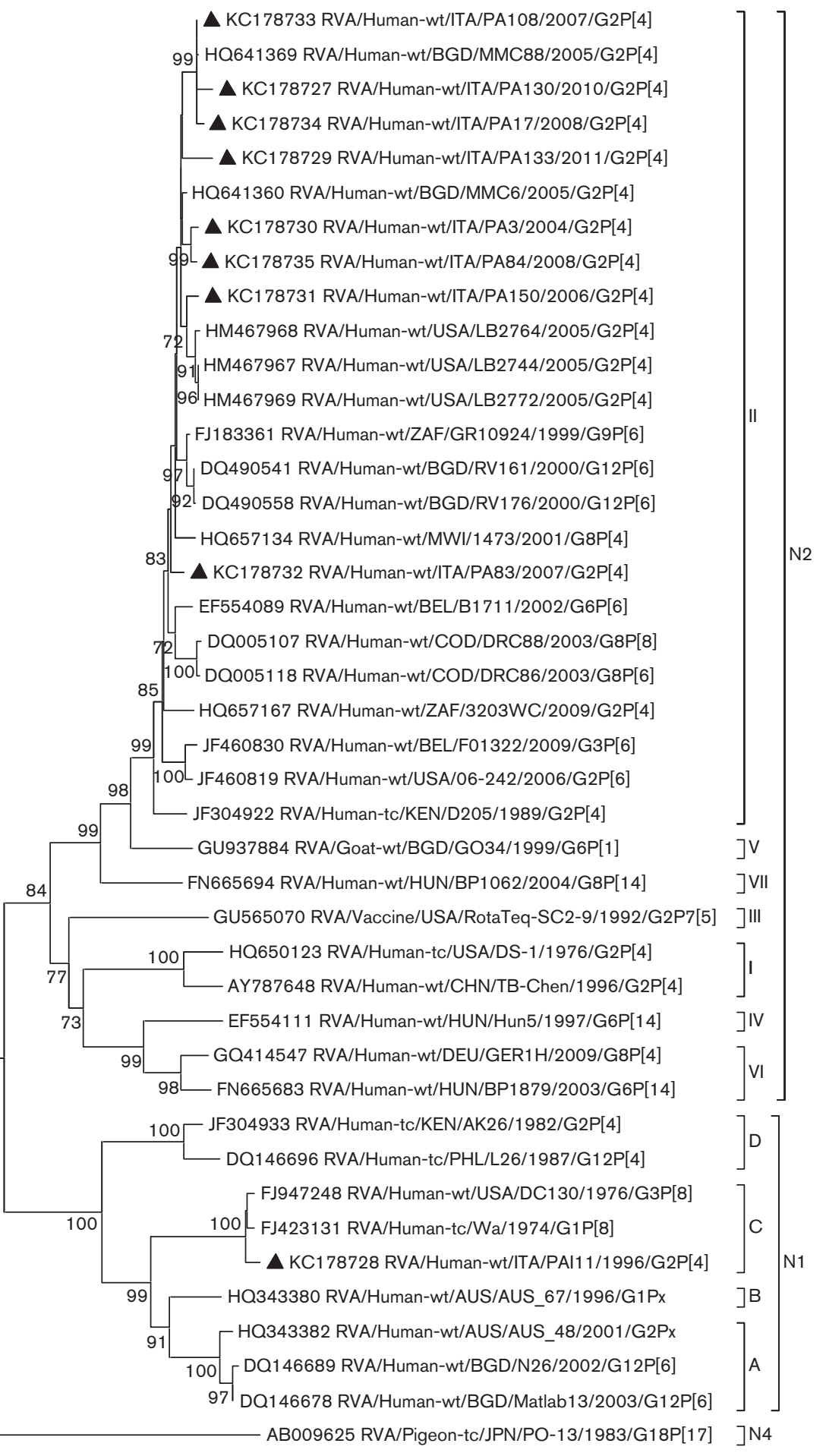

Fig. 2. (continued)

(lineage IV) possessed conserved amino acid differences at 11 residues (seven in the VRs) when compared with strain PAI11/1996 and 10 conserved different residues (seven in VRs) when compared with DS-1. In addition, several scattered variable amino acid mutations were observed.
The two G2-IV sublineages (IVa-1 and IVa-3) possessed conserved differences at residues in VR1 (position 15) and VR9 (position 242). Four amino acid changes were observed throughout the VP7 antigenic epitopes (Aoki et al., 2009) among the Italian G2P[4] strains and with respect to DS-1 
(i)

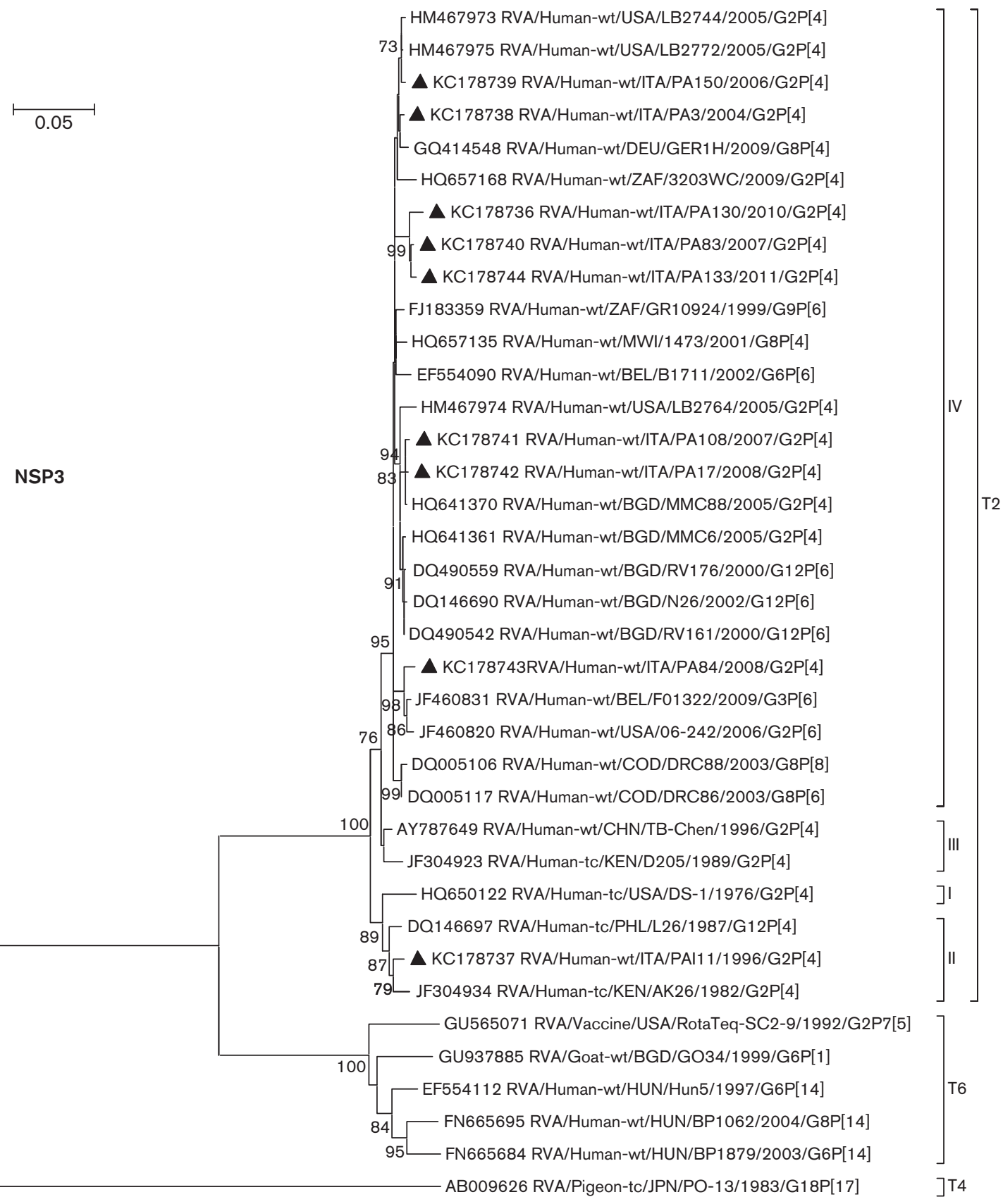

Fig. 2. (continued)

and SC2-9 strains, specifically at positions 87 and 96 in domain 7-1a, 213 in 7-1b and 242 in 7-2, corresponding to the four amino acids previously recognized as potential epitopes for G2 strains to be distinguished in lineages and sublineages (Fig. 3) (Doan et al., 2011).

In the VP4-based tree, strain PAI11/1996 clustered in lineage P[4]-II, while the 2004-2011 RVAs clustered into two distinct P[4]-IV sublineages. Strains PA3/2004, PA150/ 2006 and PA84/2008 segregated into sublineage IVa, while the majority of the more recent Italian strains (PA83/2007, PA108/2007, PA17/2008, PA130/2010 and PA133/2011) segregated into sublineage IVb (Fig. 2b). When the VP4 amino acid sequences were inspected, overall the G2P[4] strains isolated in Palermo during the surveillance period accumulated mutations at seven different amino acid positions in the antigenic epitopes of $\mathrm{VP} 8^{\star}$ and $\mathrm{VP} 5^{\star}$ with respect to the ancestor DS- 1 strain (lineage I) (Figs 4 and 5). Lineage II strain PAI11/1996 showed two differences 


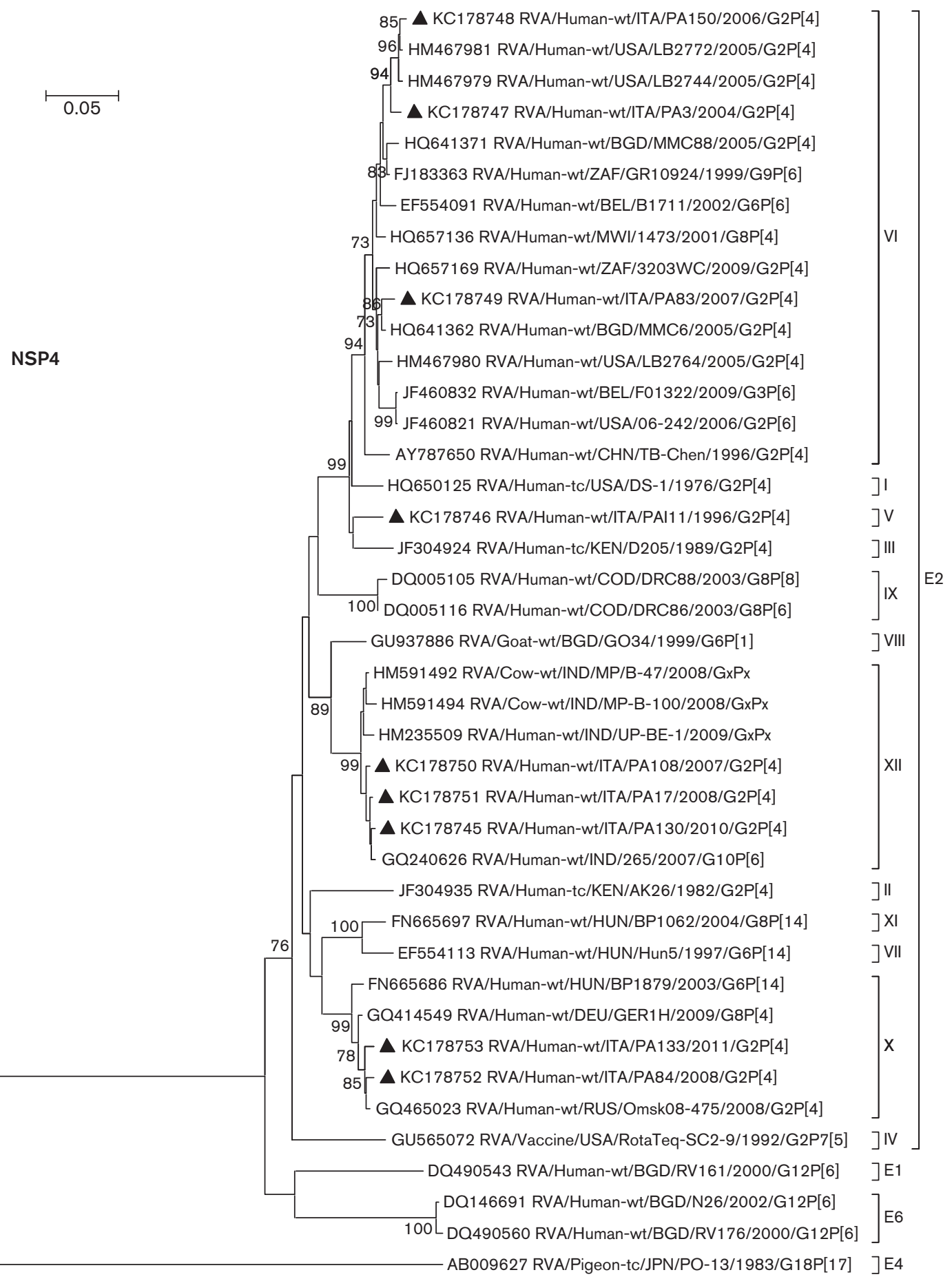

Fig. 2. (continued)

from DS- 1 in the 8-1 epitope and one in the 8-4 epitope, and three changes in VP5* epitope $5-1$. Five of the amino acid differences detected in PAI11/1996 were maintained in sublineage IVa and IVb strains from Palermo which also differed from DS-1 at residue 133 in epitope 8-3 (N133S), while position 192 reverted to A as in DS-1. A single conserved difference was observed between the amino acid sequences of the IVa and IVb sublineages at position 607 (V607I), outside the VP8* variable region (aa 72-203) and $\mathrm{VP}^{\star}$ epitopes. However, in the VP8 ${ }^{\star}$ variable region, residue 162 was either $R$ or $G$ in sublineage IVa sequences but either $\mathrm{R}$ or $\mathrm{K}$ in sublineage $\mathrm{IVb}$. 
$(\mathrm{k})$

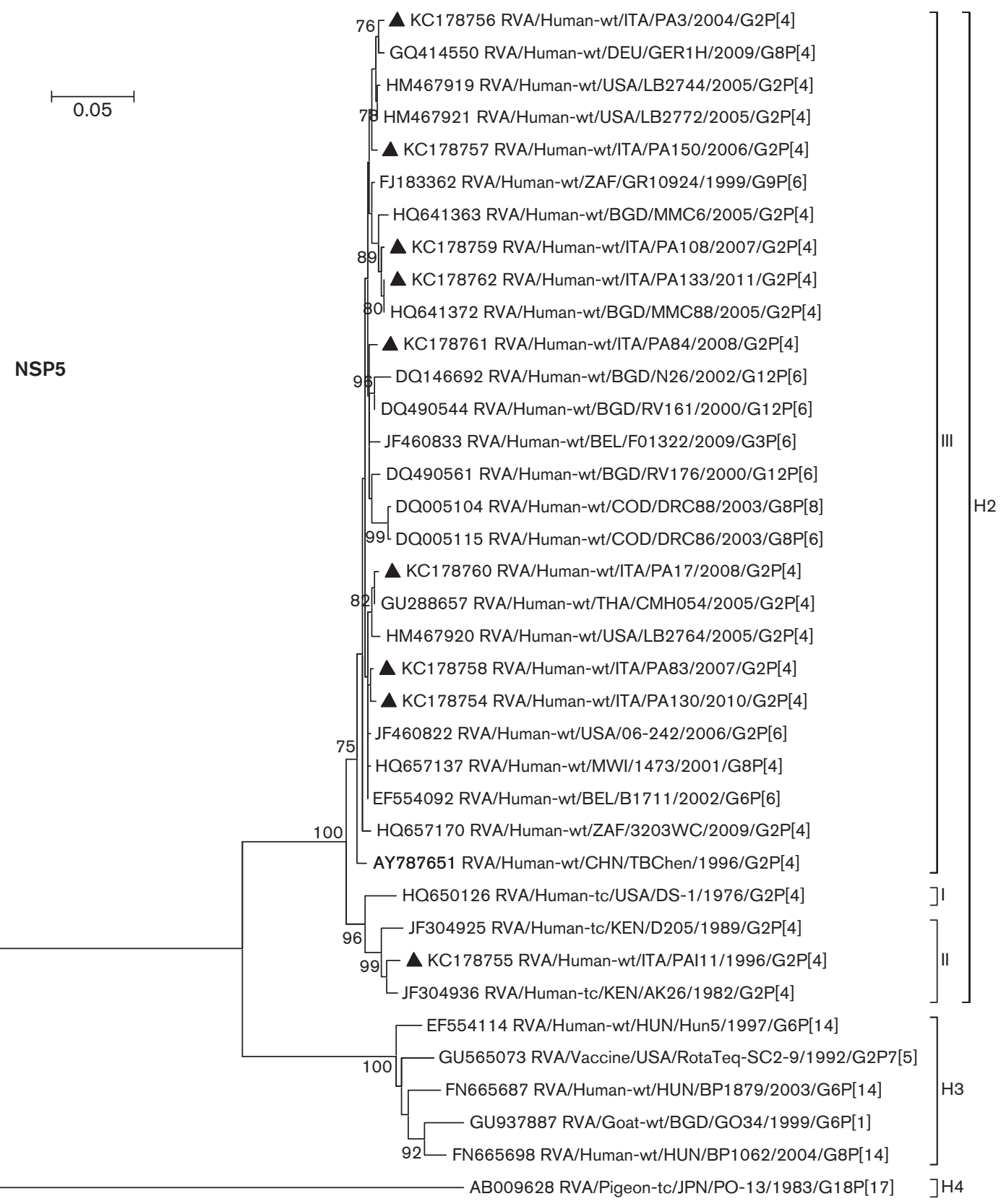

Fig. 2. (continued)

\section{CONCLUSIONS}

During a 26-year (1985-2011) surveillance in Palermo, Italy, the prevalence of G2P[4] RVAs appeared to vary yearly. An increased prevalence of G2P[4] RVAs was monitored in 1985 (9.7\%), 1996 to 1998 (49\%, 35.3\% and $6.7 \%$, respectively), 2003 (22.6\%), 2004 (4.9\%), 2006 to 2008 (4.3\%, $14 \%$ and $5.6 \%$, respectively), 2010 (5\%) and $2011(15.4 \%)$. The complete genomes of nine G2P[4] RVA strains representative of seven different seasons with increased circulation of G2 RVAs and collected between 1996 and 2011 were used to explore their genetic diversity in more detail. Based on VP7 phylogeny (Fig. 2a) and sequence analysis of the VP7 antigenic regions (Fig. 3), the old strain PAI11/1996 was assigned to lineage II, while the 2004-2006 strains and the 2007-2011 RVAs clustered in sublineage IVa-1 and sublineage IVa-3, respectively. Indepth data mining of the sequence databases has revealed that RVAs of lineage G2-II were circulating mostly during the 1990s, reaching a global distribution, with the exception of Asia (Doan et al., 2011). RVAs of lineage G2-IV dominated globally in the 2000s, with two distinct sublineages, IVa-1 and IVa-3, emerging consecutively. The two sublineages differ in their VP7 amino acid 


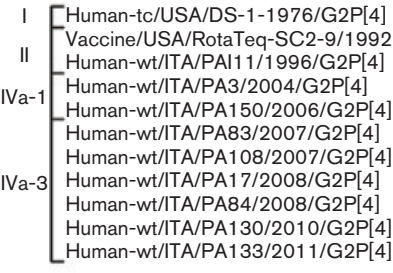

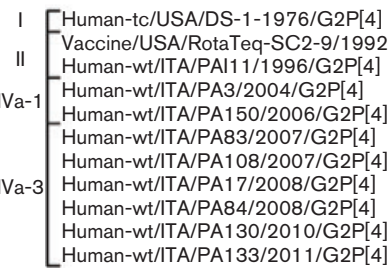
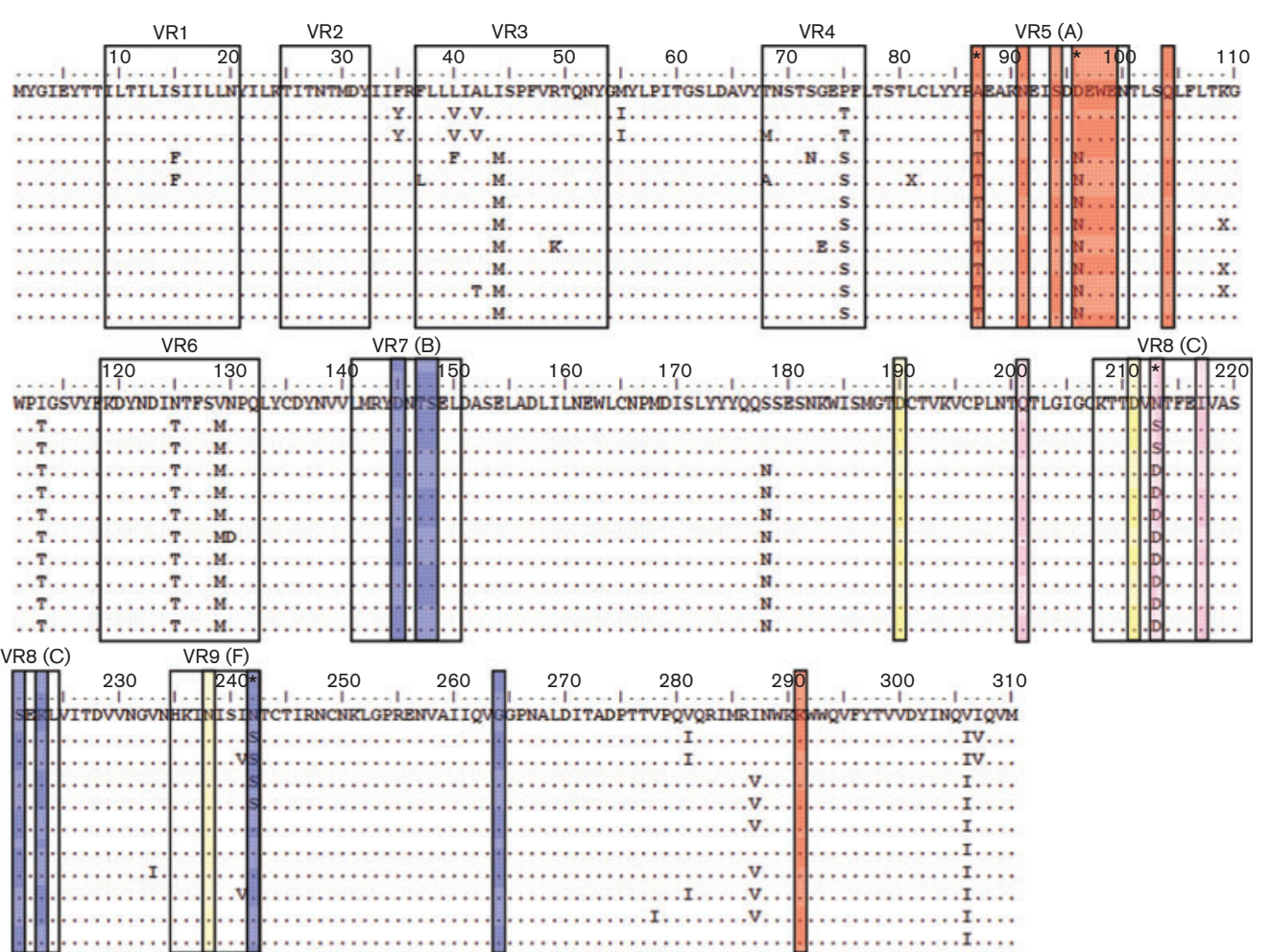

Fig. 3. Deduced amino acid sequences of the VP7 genes of Italian G2P[4] strains compared with the DS-1 G2 reference and SC2-9 vaccine strain. Antigenic variable regions (VR) are boxed. Positions of antigenic epitopes 7-1a (red), 7-1b (pink) and 7-2 (blue) and glycosylation sites (yellow) are coloured. Dots indicate conserved positions. Lineages and sublineages within genotype G2 are indicated as defined by Doan et al. (2011) based on the amino acids at residues 87, 96, 213 and 242 (indicated by asterisks).

sequence at position 242 but share, at position 96, the asparagine residue that disrupts a G2-specific monoclonal epitope (Arista et al., 2005; Doan et al., 2011). In Italy, G2 RVAs of sublineage IVa-1 circulated from 2004 to 2006 and they were replaced by G2 RVAs of sublineage IVa-3 in the 2007-2011 period. A similar shift from sublineage G2IVa-1 to G2-IVa-3 was also observed on a global scale approximately in the same period (Doan et al., 2011; Gómez et al., 2011; Mascarenhas et al., 2010). Similarly, upon phylogenetic analysis of the VP4 gene (Fig. 2b) and sequence analysis of VP4 (Fig. 4), the old Italian strain PAI11/1996 was classified as a distinct lineage, P[4]-II, while the 2000s Italian strains were classified into two different sublineages that emerged consecutively, here named P[4]-IVa and -IVb. The emergence and spread of P[4] RVAs of lineage IV during the 2000s has also been documented elsewhere (Gómez et al., 2011) and, on the basis of database interrogation, seems to have occurred worldwide. Accordingly, there is evidence that in the 2000s the shift from the VP7 sublineage G2-IVa-1 to G2-IVa-3 occurred in parallel with the shift from the VP4 sublineage $\mathrm{P}[4]-\mathrm{IV}$ a to $\mathrm{P}[4]-\mathrm{IVb}$, leading to the global spread of a unique VP7/VP4 combination, G2-IVa-3/P[4]-IVb.

In this study, we tried to understand whether the onset and spread of recent G2P[4] RVAs was also associated with reassortment events in their genome. Interestingly, upon whole genome analysis, the older strain PAI11/1996 displayed not only VP7/VP4 lineages distinct from contemporary G2P[4] RVAs, but also a distinct genomic lineage constellation. Strain PAI11/1996 was closely related to the ancient African strain AK26 in all genome segments except for NSP2 and NSP4. Strain AK26 was described as a DS-1-like inter-genogroup reassortant strain with a Walike NSP2 (N1). Also, the VP1 and NSP4 genes of this African strain appeared to originate from or share a common origin with RVA genes of artiodactyl (ruminant and camelid) origin (Ghosh et al., 2011). However, the NSP2 gene of PAI11/1996 belonged to a different N1 lineage with respect to strain AK26. G2 RVAs with an N1 NSP2 are uncommon but they have been described in Japan in six consecutive rotavirus seasons, from 1985 to 1990 (Doan et al., 2012). The prototype Japanese intergenogroup reassortant G2P[4] strain (AU605) was closely related to strain TB-Chen, and compared with PAI11/1996 belonged to different lineages in all genome segments except VP6 (data not shown). These findings are consistent with the independent origin of the Italian heterotypic NSP2 mono-reassortant strain. Interestingly, in Japan the circulation of NSP2 mono-reassortant strains was observed in seasons when $\mathrm{G} 2 \mathrm{P}[4]$ was not the most prevalent genotype 

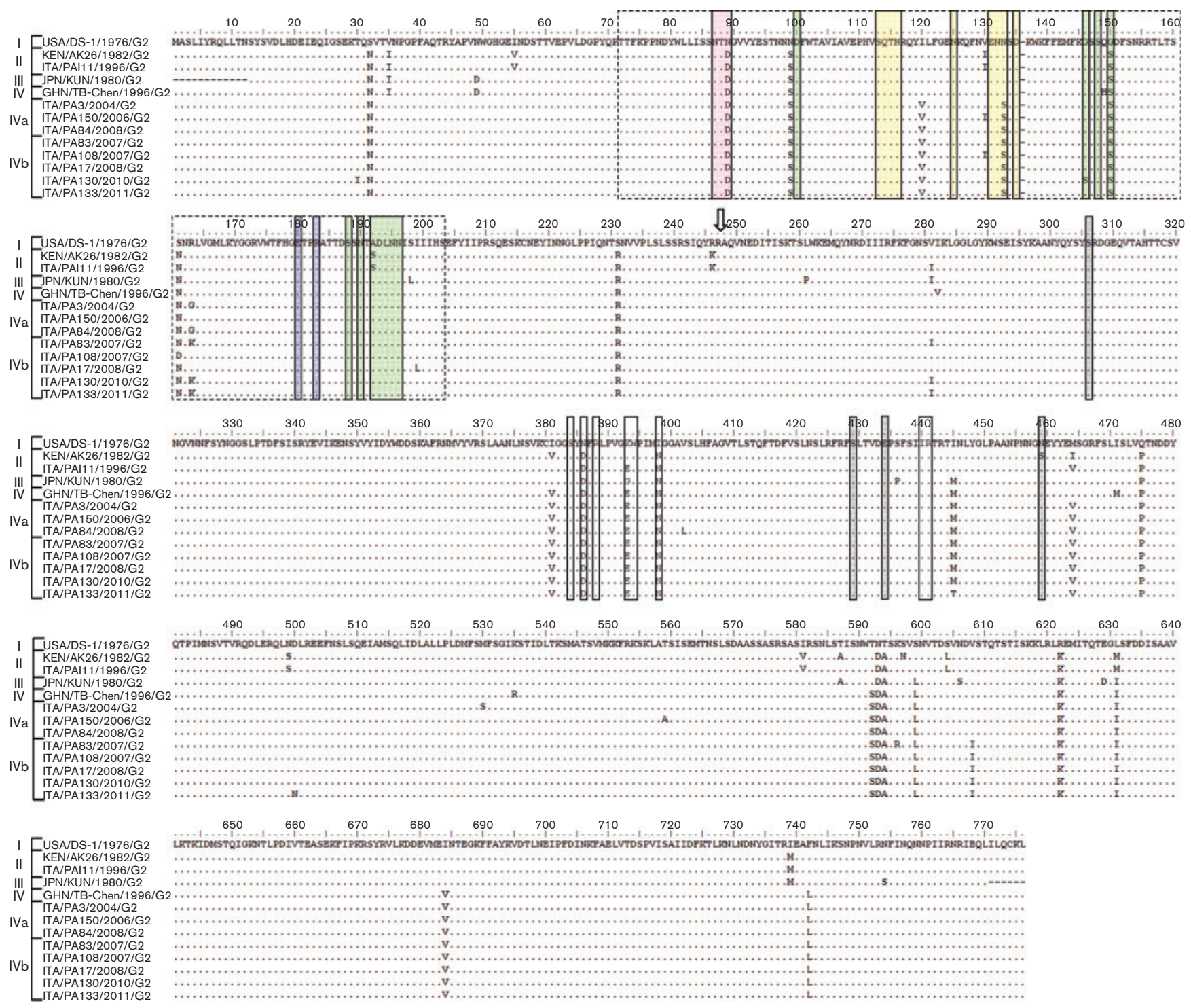

Fig. 4. Deduced amino acid sequences of the VP4 protein of P[4] strains belonging to different lineages and sublineages. Positions boxed are situated inside the VP8* variable region (aa 72-203). Residue numbering is based on the RRV sequence AY033150. Colour coding is used for residues involved in neutralization escape in VP8* (epitope 8-1, green; 8-2, blue; 8-3, yellow; 8-4, pink) and VP5* (epitope 5-1, white; 5-2 [aa 434], 5-3 [aa 459], 5-4 [aa 429] and 5-5[aa 306], grey).

(Doan et al., 2012). Although we have no evidence that all the G2P[4] strains circulating in Palermo in 1996 were NSP2 mono-reassortants, VP7 sequencing data from multiple strains from the 1996 epidemic of G2P[4] suggest that PAI11/1996 represented the epidemic strains that were predominant in Palermo in 1996 (Figs 1 and S1).

All the contemporary G2P[4] strains (circulating from 2004 to 2011) belonged to a novel lineage constellation, distinct from the reference strain DS-1 and from the RVA strains with DS-1-like genotype constellations circulating in the 1990s. This novel 2000s lineage constellation also included strains identified from Bangladesh (MMC6), South Africa (3203WC) and the USA (LB2772), all of which were circulating in the mid 2000s. Strain LB2772 was closely related to reassortant G3P[6] RVA strains infecting infants in Belgium, and to G2P[6] strains identified in the USA in 2006 (Heylen et al., 2013). Interestingly, several DS1-like non-G2P[4] strains circulating between 1999 and 2003 were already displaying a similar set of genome segments, thus suggesting that these novel 2000s G2P[4] viruses were already circulating at the end of the 1990s. Starting from 2007, several of the Italian G2P[4] strains within this novel 2000s variant of the DS-1-like genotype constellation proved to be reassortant in one or more gene segments (VP1, VP3 and/or NSP4) with RVAs of potential artiodactyl origin. The number of intra-genotype reassortment 
Front

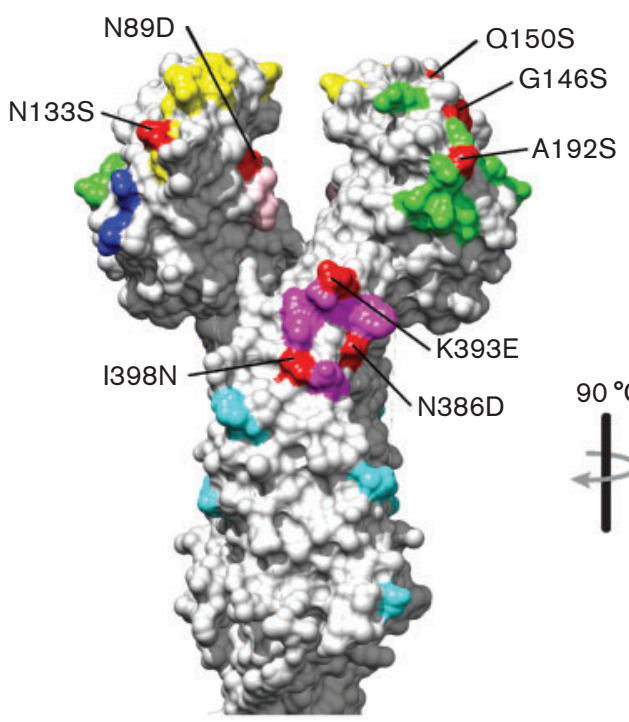

8-1
8-2 8-3 8-4

Amino acid differences
Side

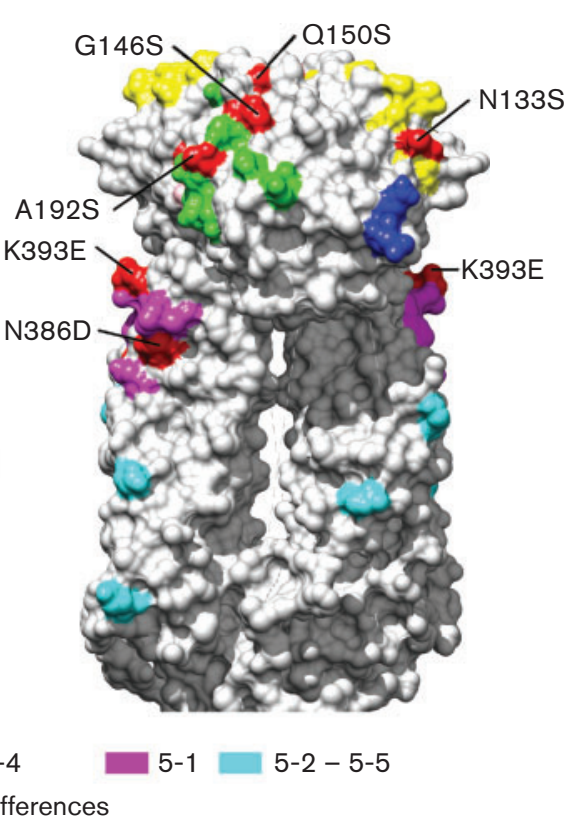

Fig. 5. Surface representation of the VP4 protein VP8* and VP5* antigenic regions. The VP4 model is based on RRV (PDB $3 I Y U)$. The right image is rotated $90^{\circ}$ compared with the left image. Antigenic epitopes are coloured in green (8-1), blue (8-2), yellow (8-3), pink (8-4), purple (5-1) and cyan (5-2 to 5-5). Surface-exposed residues that differ between strains circulating in Palermo and the DS-1 strain are shown in red.

events in contemporary G2P[4] RVA strains suggests a certain tendency to acquisition of gene segments from animal RVAs when genome segments share the same genotype. From 2007 to 2011, VP1 and VP3 genes closely related with a caprine strain (GO34) from Bangladesh and NSP4 gene segments closely related to those of RVA strains identified from cows in India were detected in G2P[4] RVAs of the novel 2000s variant in Palermo. Similarly, several intra-genogroup reassortment events have been identified within G2P[4] strains co-circulating in the 20052006 season in the USA (Bányai et al., 2011). The G2P[4] RVAs circulating in the earlier 2000s appear to be more homogeneous genetically, suggesting that the G2P[4] RVAs detected in the 2000s started to acquire novel gene segments via reassortment only some years after their global spread. Multi-centric investigations analysing a larger number of old and novel G2P[4] RVAs detected in the 2000s from different geographical areas could allow better explanation of the global evolution of G2P[4] RVAs in the last decades and eventually reveal additional gene polymorphisms.

In 2006, two RVA vaccines were licensed and they are now included as part of the routine vaccination schedule for infants in many countries around the world (Ciarlet \& Schödel, 2009; Heaton \& Ciarlet, 2007; Matthijnssens et al., 2010). None of the currently licensed RVA vaccines contains strains with a complete DS-1-like genotype constellation (Matthijnssens \& Van Ranst, 2012). In addition, the VP7 of the SC2-9 G2-reassortant strain of Rotateq vaccine originates from the tissue culture-adapted parent human RVA strain SC2, dating back to the early 1980s (Matthijnssens et al., 2010). The G2 VP7 of the SC-2 strain belongs to the same lineage as PAI11/1996 (lineage II), but this strain appears to be distantly related to contemporary 2000s G2 strains (Fig. 2), with up to four amino acid differences being observed in the VP7 antigenic epitopes of the most recent Italian strains (Fig. 3). A similar accumulation of mutations in the amino acid sequences of VP7 was observed in Belgian G2 strains post vaccine introduction (Zeller et al., 2012). It is unclear whether the major modifications observed in the neutralizing antigens and in the genome composition of modern G2P[4] RVAs are related, to some extent, to the global introduction of the RVA vaccines. Epidemiological investigations after the introduction of RVA vaccines have reported increased circulation of G2P[4] strains in some countries (Gurgel et al., 2007; Nakagomi et al., 2008; Zeller et al., 2010). However, long-term surveillance studies indicate that large fluctuations in the prevalence of G2P[4] RVAs had also occurred before the introduction of the RVA vaccines (Bányai et al., 2012).

Large-scale surveillance studies and whole genome sequencing are quickly generating a massive amount of data and providing new insights into the mechanisms driving the 
evolution of RVAs (Matthijnssens et al., 2008a, 2011). It is now clear that human RVAs are subjected to a continual transformation involving accumulation of point mutations, reassortment and repeated intersections with the evolution of animal RVAs (Martella et al., 2011). On the basis of our findings, modern G2P[4] RVAs appear to represent an excellent paradigm of this model.

\section{REFERENCES}

Antunes, H., Afonso, A., Iturriza, M., Martinho, I., Ribeiro, C., Rocha, S., Magalhães, C., Carvalho, L., Branca, F. \& Gray, J. (2009). G2P[4] the most prevalent rotavirus genotype in 2007 winter season in an European non-vaccinated population. J Clin Virol 45, 76-78.

Aoki, S. T., Settembre, E. C., Trask, S. D., Greenberg, H. B., Harrison, S. C. \& Dormitzer, P. R. (2009). Structure of rotavirus outer-layer protein VP7 bound with a neutralizing Fab. Science 324, 1444-1447.

Arista, S., Giovannelli, L., Passarani, N., Titone, L. \& Gerna, G. (1986). Electropherotyping of human rotaviruses: an epidemiological survey of rotavirus infections in Sicily. Eur J Epidemiol 2, 104-107.

Arista, S., Giovannelli, L., Pistoia, D., Cascio, A., Parea, M. \& Gerna, G. (1990). Electropherotypes, subgroups and serotypes of human rotavirus strains causing gastroenteritis in infants and young children in Palermo, Italy, from 1985 to 1989. Res Virol 141, 435-448.

Arista, S., Vizzi, E., Ferraro, D., Cascio, A. \& Di Stefano, R. (1997). Distribution of VP7 serotypes and VP4 genotypes among rotavirus strains recovered from Italian children with diarrhea. Arch Virol 142, 2065-2071.

Arista, S., Vizzi, E., Migliore, M. C., Di Rosa, E. \& Cascio, A. (2003). High incidence of G9P181 rotavirus infections in Italian children during the winter season 1999-2000. Eur J Epidemiol 18, 711-714.

Arista, S., Giammanco, G. M., De Grazia, S., Migliore, M. C., Martella, V. \& Cascio, A. (2004). Molecular characterization of the genotype G9 human rotavirus strains recovered in Palermo, Italy, during the winter of 1999-2000. Epidemiol Infect 132, 343-349.

Arista, S., Giammanco, G. M., De Grazia, S., Colomba, C., Martella, V., Cascio, A. \& Iturriza-Gòmara, M. (2005). G2 rotavirus infections in an infantile population of the south of Italy: variability of viral strains over time. J Med Virol 77, 587-594.

Bányai, K., Papp, H., Dandár, E., Molnár, P., Mihály, I., Van Ranst, M., Martella, V. \& Matthijnssens, J. (2010). Whole genome sequencing and phylogenetic analysis of a zoonotic human G8P[14] rotavirus strain. Infect Genet Evol 10, 1140-1144.

Bányai, K., Mijatovic-Rustempasic, S., Hull, J. J., Esona, M. D., Freeman, M. M., Frace, A. M., Bowen, M. D. \& Gentsch, J. R. (2011). Sequencing and phylogenetic analysis of the coding region of six common rotavirus strains: evidence for intragenogroup reassortment among co-circulating $\mathrm{G} 1 \mathrm{P}[8]$ and $\mathrm{G} 2 \mathrm{P}[4]$ strains from the United States. J Med Virol 83, 532-539.

Bányai, K., László, B., Duque, J., Steele, A. D., Nelson, E. A., Gentsch, J. R. \& Parashar, U. D. (2012). Systematic review of regional and temporal trends in global rotavirus strain diversity in the pre rotavirus vaccine era: insights for understanding the impact of rotavirus vaccination programs. Vaccine 30 (Suppl. 1), A122A130.

Chouikha, A., Fodha, I., Ben Hadj Fredj, M., Ardhaoui, M., Teleb, N., Brini, I., Messaadi, F., Mastouri, M., Sfar, T. \& other authors (2011). Relationship between electropherotypes and VP7/VP4 genotypes of group A rotaviruses detected between 2000 and 2007 in Tunisian children. Pathol Biol (Paris) 59, e43-e48.
Ciarlet, M. \& Schödel, F. (2009). Development of a rotavirus vaccine: clinical safety, immunogenicity, and efficacy of the pentavalent rotavirus vaccine, RotaTeq. Vaccine 27 (Suppl. 6), G72-G81.

De Grazia, S., Ramirez, S., Giammanco, G. M., Colomba, C., Martella, V., Lo Biundo, C., Mazzola, R. \& Arista, S. (2007). Diversity of human rotaviruses detected in Sicily, Italy, over a 5year period (2001-2005). Arch Virol 152, 833-837.

Dey, S. K., Hayakawa, Y., Rahman, M., Islam, R., Mizuguchi, M., Okitsu, S. \& Ushijima, H. (2009). G2 strain of rotavirus among infants and children, Bangladesh. Emerg Infect Dis 15, 91-94.

Doan, Y. H., Nakagomi, T., Cunliffe, N. A., Pandey, B. D., Sherchand, J. B. \& Nakagomi, O. (2011). The occurrence of amino acid substitutions D96N and S242N in VP7 of emergent G2P[4] rotaviruses in Nepal in 2004-2005: a global and evolutionary perspective. Arch Virol 156, 1969-1978.

Doan, Y. H., Nakagomi, T. \& Nakagomi, O. (2012). Repeated circulation over 6 years of intergenogroup mono-reassortant G2P[4] rotavirus strains with genotype N1 of the NSP2 gene. Infect Genet Evol 12, 1202-1212.

Donker, N. C., Boniface, K. \& Kirkwood, C. D. (2011). Phylogenetic analysis of rotavirus A NSP2 gene sequences and evidence of intragenic recombination. Infect Genet Evol 11, 1602-1607.

Estes, M. K. \& Kapikian, A. Z. (2007). Rotaviruses, 5th edn, vol. 2. Philadelphia: Lippincott, Williams \& Wilkins.

Gentsch, J. R., Glass, R. I., Woods, P., Gouvea, V., Gorziglia, M., Flores, J., Das, B. K. \& Bhan, M. K. (1992). Identification of group A rotavirus gene 4 types by polymerase chain reaction. J Clin Microbiol 30, 1365-1373.

Ghosh, S., Adachi, N., Gatheru, Z., Nyangao, J., Yamamoto, D., Ishino, M., Urushibara, N. \& Kobayashi, N. (2011). Whole-genome analysis reveals the complex evolutionary dynamics of Kenyan G2P[4] human rotavirus strains. J Gen Virol 92, 2201-2208.

Gómez, M. M., de Mendonça, M. C., Volotão, E. M., Tort, L. F., da Silva, M. F., Cristina, J. \& Leite, J. P. (2011). Rotavirus A genotype P[4]G2: genetic diversity and reassortment events among strains circulating in Brazil between 2005 and 2009. J Med Virol 83, 10931106.

Gouvea, V., Glass, R. I., Woods, P., Taniguchi, K., Clark, H. F., Forrester, B. \& Fang, Z. Y. (1990). Polymerase chain reaction amplification and typing of rotavirus nucleic acid from stool specimens. J Clin Microbiol 28, 276-282.

Gurgel, R. Q., Cuevas, L. E., Vieira, S. C., Barros, V. C., Fontes, P. B., Salustino, E. F., Nakagomi, O., Nakagomi, T., Dove, W. \& other authors (2007). Predominance of rotavirus P[4]G2 in a vaccinated population, Brazil. Emerg Infect Dis 13, 1571-1573.

Heaton, P. M. \& Ciarlet, M. (2007). Vaccines: the pentavalent rotavirus vaccine: discovery to licensure and beyond. Clin Infect Dis 45, 16181624.

Heylen, E., Zeller, M., Ciarlet, M., De Coster, S., Van Ranst, M. \& Matthijnssens, J. (2013). Complete genetic characterization of human G2P[6] and G3P[6] rotavirus strains. Infect Genet Evol 13, 27-35.

Iturriza-Gomara, M., Green, J., Brown, D. W., Desselberger, U. \& Gray, J. J. (1999). Comparison of specific and random priming in the reverse transcriptase polymerase chain reaction for genotyping group A rotaviruses. J Virol Methods 78, 93-103.

Iturriza-Gómara, M., Kang, G. \& Gray, J. (2004). Rotavirus genotyping: keeping up with an evolving population of human rotaviruses. J Clin Virol 31, 259-265.

Iturriza-Gómara, M., Dallman, T., Bányai, K., Böttiger, B., Buesa, J., Diedrich, S., Fiore, L., Johansen, K., Koopmans, M. \& other authors (2011). Rotavirus genotypes co-circulating in Europe between 2006 
and 2009 as determined by EuroRotaNet, a pan-European collaborative strain surveillance network. Epidemiol Infect 139, 895-909.

Kirkwood, C. D., Boniface, K., Bishop, R. F., Barnes, G. L. \& Australian Rotavirus Surveillance Group (2009). Australian Rotavirus Surveillance Program annual report, 2008/2009. Commun Dis Intell Q Rep 33, 382-388.

Maes, P., Matthijnssens, J., Rahman, M. \& Van Ranst, M. (2009). RotaC: a web-based tool for the complete genome classification of group A rotaviruses. BMC Microbiol 9, 238.

Martella, V., Terio, V., Arista, S., Elia, G., Corrente, M., Madio, A., Pratelli, A., Tempesta, M., Cirani, A. \& Buonavoglia, C. (2004). Nucleotide variation in the VP7 gene affects PCR genotyping of G9 rotaviruses identified in Italy. J Med Virol 72, 143-148.

Martella, V., Potgieter, A. C., Lorusso, E., De Grazia, S., Giammanco, G. M., Matthijnssens, J., Bányai, K., Ciarlet, M., Lavazza, A. \& other authors (2011). A feline rotavirus G3P[9] carries traces of multiple reassortment events and resembles rare human G3P[9] rotaviruses. J Gen Virol 92, 1214-1221.

Mascarenhas, J. D., Lima, C. S., de Oliveira, D. S., Guerra, S. F., Maestri, R. P., Gabbay, Y. B., de Lima, I. C., de Menezes, E. M., Linhares, A. C. \& Bensabath, G. (2010). Identification of two sublineages of genotype G2 rotavirus among diarrheic children in Parauapebas, Southern Pará State, Brazil. J Med Virol 82, 712 719.

Matthijnssens, J. \& Van Ranst, M. (2012). Genotype constellation and evolution of group A rotaviruses infecting humans. Curr Opin Virol 2, 426-433.

Matthijnssens, J., Rahman, M., Martella, V., Xuelei, Y., De Vos, S., De Leener, K., Ciarlet, M., Buonavoglia, C. \& Van Ranst, M. (2006). Full genomic analysis of human rotavirus strain B4106 and lapine rotavirus strain $30 / 96$ provides evidence for interspecies transmission. J Virol 80, 3801-3810.

Matthijnssens, J., Ciarlet, M., Heiman, E., Arijs, I., Delbeke, T., McDonald, S. M., Palombo, E. A., Iturriza-Gómara, M., Maes, P. \& other authors (2008a). Full genome-based classification of rotaviruses reveals a common origin between human Wa-Like and porcine rotavirus strains and human DS-1-like and bovine rotavirus strains. J Virol 82, 3204-3219.

Matthijnssens, J., Ciarlet, M., Rahman, M., Attoui, H., Bányai, K., Estes, M. K., Gentsch, J. R., Iturriza-Gómara, M., Kirkwood, C. D. \& other authors (2008b). Recommendations for the classification of group A rotaviruses using all 11 genomic RNA segments. Arch Virol $153,1621-1629$.

Matthijnssens, J., Bilcke, J., Ciarlet, M., Martella, V., Bányai, K., Rahman, M., Zeller, M., Beutels, P., Van Damme, P. \& Van Ranst, M. (2009). Rotavirus disease and vaccination: impact on genotype diversity. Future Microbiol 4, 1303-1316.

Matthijnssens, J., Joelsson, D. B., Warakomski, D. J., Zhou, T., Mathis, P. K., van Maanen, M. H., Ranheim, T. S. \& Ciarlet, M. (2010). Molecular and biological characterization of the 5 human-bovine rotavirus (WC3)-based reassortant strains of the pentavalent rotavirus vaccine, RotaTeq. Virology 403, 111-127.
Matthijnssens, J., Ciarlet, M., McDonald, S. M., Attoui, H., Bányai, K., Brister, J. R., Buesa, J., Esona, M. D., Estes, M. K. \& other authors (2011). Uniformity of rotavirus strain nomenclature proposed by the Rotavirus Classification Working Group (RCWG). Arch Virol 156, 1397-1413.

Matthijnssens, J., Nakagomi, O., Kirkwood, C. D., Ciarlet, M., Desselberger, U. \& Van Ranst, M. (2012). Group A rotavirus universal mass vaccination: how and to what extent will selective pressure influence prevalence of rotavirus genotypes? Expert Rev Vaccines 11, 1347-1354.

Nakagomi, T. \& Nakagomi, O. (1989). RNA-RNA hybridization identifies a human rotavirus that is genetically related to feline rotavirus. J Virol 63, 1431-1434.

Nakagomi, T., Cuevas, L. E., Gurgel, R. G., Elrokhsi, S. H., Belkhir, Y. A., Abugalia, M., Dove, W., Montenegro, F. M., Correia, J. B. \& other authors (2008). Apparent extinction of non-G2 rotavirus strains from circulation in Recife, Brazil, after the introduction of rotavirus vaccine. Arch Virol 153, 591-593.

Paul, S. K., Kobayashi, N., Nagashima, S., Ishino, M., Watanabe, S., Alam, M. M., Ahmed, M. U., Hossain, M. A. \& Naik, T. N. (2008). Phylogenetic analysis of rotaviruses with genotypes G1, G2, G9 and G12 in Bangladesh: evidence for a close relationship between rotaviruses from children and adults. Arch Virol 153, 1999-2012.

Santos, N. \& Hoshino, Y. (2005). Global distribution of rotavirus serotypes/genotypes and its implication for the development and implementation of an effective rotavirus vaccine. Rev Med Virol 15, 29-56.

Tamura, K., Peterson, D., Peterson, N., Stecher, G., Nei, M. \& Kumar, S. (2011). MEGA5: molecular evolutionary genetics analysis using maximum likelihood, evolutionary distance, and maximum parsimony methods. Mol Biol Evol 28, 2731-2739.

Tate, J. E., Burton, A. H., Boschi-Pinto, C., Steele, A. D., Duque, J., Parashar, U. D. \& WHO-coordinated Global Rotavirus Surveillance Network (2012). 2008 estimate of worldwide rotavirus-associated mortality in children younger than 5 years before the introduction of universal rotavirus vaccination programmes: a systematic review and meta-analysis. Lancet Infect Dis 12, 136-141.

Todd, S., Page, N. A., Duncan Steele, A., Peenze, I. \& Cunliffe, N. A. (2010). Rotavirus strain types circulating in Africa: review of studies published during 1997-2006. J Infect Dis 202 (Suppl.), S34-S42.

Trojnar, E., Sachsenröder, J., Twardziok, S., Reetz, J., Otto, P. H. \& Johne, R. (2013). Identification of an avian group A rotavirus containing a novel VP4 gene with a close relationship to those of mammalian rotaviruses. J Gen Virol 94, 136-142.

Zeller, M., Rahman, M., Heylen, E., De Coster, S., De Vos, S., Arijs, I., Novo, L., Verstappen, N., Van Ranst, M. \& Matthijnssens, J. (2010). Rotavirus incidence and genotype distribution before and after national rotavirus vaccine introduction in Belgium. Vaccine 28, 7507-7513.

Zeller, M., Patton, J. T., Heylen, E., De Coster, S., Ciarlet, M., Van Ranst, M. \& Matthijnssens, J. (2012). Genetic analyses reveal differences in the VP7 and VP4 antigenic epitopes between human rotaviruses circulating in Belgium and rotaviruses in Rotarix and RotaTeq. J Clin Microbiol 50, 966-976. 